\title{
Too-Systemic-To-Fail: What Option Markets Imply About Sector-wide Government Guarantees*
}

\author{
Bryan Kelly \\ Hanno Lustig \\ Chicago Booth \\ UCLA Anderson and NBER \\ Stijn Van Nieuwerburgh \\ NYU Stern, NBER, and CEPR
}

December 15, 2011

\footnotetext{
*First draft: February 15, 2011. We thank Mikhail Chernov, Peter Christoffersen, John Cochrane, George Constantinides, Joshua Coval, Itamar Drechsler, Darrell Duffie, Willie Fuchs, Stefano Giglio, Ralph Koijen, Martin Lettau, Matteo Maggiore, Marc Martos-Vila, Pascal Maenhout, Ian Martin, Robert McDonald, Thomas Philippon, Richard Roll, Mark Rubenstein, Stephen Ross, Rene Stulz, Ingrid Werner and seminar participants at SITE, Chicago Booth, USC, Berkeley, UCLA, University of Toronto, University of Utah, Tulane, Federal Reserve Bank of San Francisco, Stanford (economics and finance departments), NYU Stern, Emory, Boston College, NBER asset pricing meeting, SED annual meeting, NYU-CMU-Maryland-Berkeley conference on systemic risk, CMU macro-finance conference, and the NYU conference in honor of Thomas Sargent for comments and suggestions. We thank Erin Smith for generously sharing securities lending data.
} 


\begin{abstract}
A conspicuous amount of aggregate tail risk is missing from the price of financial sector crash insurance during the 2007-2009 crisis. The difference in costs of out-of-the-money put options for individual banks, and puts on the financial sector index, increases fourfold from its pre-crisis level. At the same time, correlations among bank stocks surge, suggesting the high put spread cannot be attributed to a relative increase in idiosyncratic risk. We show that this phenomenon is unique to the financial sector, that it cannot be explained by observed risk dynamics (volatilities and correlations), and that illiquidity and no-arbitrage violations are unlikely culprits. Instead, we provide evidence that a collective government guarantee for the financial sector lowers index put prices far more than those of individual banks, explaining the divergence in the basket-index spread. By embedding a bailout in the standard one-factor option pricing model, we can closely replicate observed put spread dynamics. During the crisis, the spread responds acutely to government intervention announcements.
\end{abstract}

Keywords: systemic risk, government bailout, too-big-to-fail, option pricing models, financial crisis

JEL codes: G12, G13, G18, G21, G28, E44, E60, H23 


\section{Introduction}

Despite wide acknowledgment as an episode of elevated systemic risk, prices of crash insurance on US financial sector equity reflect a conspicuous absence of aggregate tail risk during the crisis of 2007-2009. Out-of-the-money (OTM) put options on the financial sector stock index are cheap relative to individual put options on the individual banks that comprise the index. The difference between the cost of a basket of banks' put options, and the cost of a moneyness-matched financial sector index put, reaches 15.9 cents per dollar insured in March 2009, or $60 \%$ of the cost of the financial index put. Before the onset of the crisis, this spread never exceeded 3.8 cents on the dollar.

The high basket-index spread in the financial sector is puzzling. The basket of put options provides insurance against both common and idiosyncratic bank stock crashes, while the index put option only insures states of the world that prompt a common financial sector crash. Standard option pricing logic therefore requires a disproportionate increase in idiosyncratic risk (relative to aggregate risk) to explain a dramatic increase in the put spread. A puzzle arises because, as is common in turbulent markets, correlations among financial stocks also surge throughout the crisis. The drastic rise in idiosyncratic risks necessary to explain the put spread would counterfactually imply a sharp decrease in stock return correlations. These two facts, simultaneous spikes in correlations and the financial sector basket-index put spread, are at odds with standard asset pricing models. If anything, the standard model suggests that a rapid increase in return correlations should have raised the price of OTM index options relative to the option basket, causing the put spread to shrink.

Our findings are unique to financial sector puts. Divergence in the put spread is much larger for the financial sector than for any other sector and, consistent with the logic of the standard model, the prices of basket and index call options in all sectors converge during the crisis. Further, the phenomenon we document cannot be attributed to observed financial sector risk dynamics during the crisis. We consider the possibility that the dramatic rise in volatilities during the crisis drives the put spread wider, but find that this explains only a small portion of the spread divergence that we identify. We can rule out transactions costs, since constructing the spread using the most costly combination of bid and ask quotes continues to produce a wide basket-index put spread. Liquidity differences across various types of options (index versus individual, puts versus calls, or financial firms versus non-financials) are inconsistent with the put spread arising because of illiquidity. Mispricings due to capital constraints, counter-party risk, and short sale restrictions are unlikely culprits. A trade that takes advantage of the basket-index spread does not tie up significant capital and occurs through exchanges with a clearing house in the middle. These option positions are marked-to-market daily and ultimately guaranteed by the AAA-rated Options Clearing Corporation. The short sale ban was in place only for a brief portion of our 
sample, applied equally to individual and index options, and market makers were exempted from it. Nor do short sale lending fees for financial stocks line up with the put spread dynamics that we document.

Instead, we provide direct and indirect evidence that a sector-wide bailout guarantee was largely responsible for the divergence of individual and index put prices during the recent crisis. The anticipation of future government intervention during a financial sector collapse would depress markets for crash insurance. In effect, implicit bailout guarantees are crash insurance subsidies for anyone holding stock in the banking sector, and this subsidy drives down the prices investors were willing to pay for the traded, private version of insurance. Since any individual bank may still fail amid a collective guarantee, or the failure of a single firm may not be sufficient to trigger government intervention, the downward pressure on individual bank puts is much weaker than the effect on index puts. Looking at this effect through the lens of the well-documented put option implied volatility skew, we show that the government's guarantee flattens the volatility skew for put options on the financial sector index, but has little effect on the individual bank put skew. We find no evidence of skew flattening for non-financial indices.

A standard option pricing model, perhaps unsurprisingly, fails to describe the put spread evolution observed during the crisis. However, after embedding a government guarantee in the standard model, realized volatility and correlation dynamics in the financial sector produce a model-implied put spread strikingly similar to that in the data. We argue that this analysis provides indirect evidence that a government guarantee can account for dynamics of the basket-index put spread over our sample. The most accurate match of the spread requires a government bailout that truncates the sector-wide equity return at a $55 \%$ loss. By comparing the bailout-adjusted and the standard bailout-free cost of an option-based hedge against a financial sector crash, we obtain a dollar estimate of the value of the government guarantee for the financial sector. According to this estimate, government support to banks' equity was $\$ 0.63$ billion before mid-2007 and rose to $\$ 42.38$ billion between mid-2007 and mid-2009. It peaked at well over $\$ 150$ billion.

Furthermore, an event study of the financial sector put spread evolution provides direct evidence of option price sensitivity to government guarantees. The spread increases on average by 1.64 cents $(64 \%)$ in the first five days after government announcements that ex ante increase the probability of a bailout, while it decreases on average 1.92 cents (23\%) after announcements that have the opposite effect (and after adjusting for contemporaneous changes in financial sector risk). The largest increase in the spread $(60 \%)$ was registered in the first five days after the U.S. Congress approved the TARP bailout. We also document differences in put prices across banks. Riskadjusted put prices for large banks are significantly lower than puts on their smaller peers, indicating investors perceive differences in bailout likelihoods across institutions aligned with the notion of "too-systemic-to-fail." Both of these results support the collective guarantee hypothesis. ${ }^{1}$

\footnotetext{
${ }^{1}$ One may argue that the put spread widens even in the absence of a bailout if tail risk (say, in the form of
} 
Our work connects to various strands of the literature. First, it is linked to the problem of measuring systemic risk in the financial sector. ${ }^{2}$ Our findings highlight a fundamental complication to the problem of measuring systemic risk from market prices. All else equal, the basket-index spread for OTM put options would be a natural measure of systemic risk: the smaller the basketindex spread in a sector, the larger the amount of systemic risk in that sector. However, in sectors that benefit from an implicit or explicit collective guarantee, an increase in the basket-index spread may occur when systemic risk peaks and the collective bailout guarantee is more likely to kick in. Hence, the anticipation of future government intervention is embedded in market prices today and makes them less informative about the true nature of tail risk. This feedback from anticipated corrective action to market prices echoes the problem of a board of directors looking at share prices to fire a CEO in the presence of rational investors anticipating this behavior (Bond, Goldstein, and Prescott, 2010). A similar situation arises in the context of a central bank setting interest rates via a Taylor rule, which depends on expected inflation, when agents form expectations about inflation in part based on the central bank's policy rule.

Effects of too-systemic-to-fail government guarantees remain highly uncertain and intensely researched. A number of papers measure the impact of these guarantees on the total value of the firm. Lucas and McDonald (2006, 2010) take an option-based approach to valuing guarantees extended to Fannie Mae and Freddie Mac. Veronesi and Zingales (2010) use CDS data to measure the value of government bailouts to bondholders and stockholders of the largest financial firms from the Paulson plan. They estimate that this plan increased the total value of banks' balance sheets by $\$ 131$ billion.

Our paper focuses exclusively on equity. In principle, bailouts of bondholders and other creditors do not imply that the value of equity is protected. However, there may be massive uncertainty about the resolution regime in practice, especially for large financial institutions. As a result, collective guarantees tend to benefit shareholders as well because the government is aware that bankruptcy costs start well before the value of bank equity actually hits zero. A contribution of this paper is to demonstrate that financial sector guarantees can massively prop up bank equity value. Our findings also suggests a substantial reduction in the cost of equity for systemically risky financial firms. This is consistent with Gandhi and Lustig (2010), who show that large banks have risk-adjusted equity returns $5 \%$ per annum lower than those of the smallest banks, a difference that they attribute to an implicit guarantee for large banks. In a seminal paper on this topic, O'Hara and Shaw (1990) document large positive wealth effects for shareholders of banks who were declared

high subprime mortgage exposure) is concentrated in one or two banks, but investors don't know which banks these are. We find this scenario, in which there is no real "systemic" risk, counterfactual since the government has little incentive to intervene in this situation. Alternatively, there may be a small number of banks with direct exposure to an extreme shock, with other banks having indirect tail exposure via their linkages with exposed banks. This scenario is consistent with our notion of systemic risk, and is approximated by our reduced form factor model.

${ }^{2}$ See Acharya, Pedersen, Philippon, and Richardson (2010); Adrian and Brunnermeier (2010); Brownless and Engle (2010); Huang, Zhou, and Zhu (2011) for recent advances in systemic risk measurement. 
too-big-to-fail by the Comptroller of the Currency in 1984, and negative wealth effects for those banks that were not included.

Other recent studies have also examined the relative pricing of derivative securities. Coval, Jurek, and Stafford (2009) compare the prices of CDX tranches to those of index options prior to and during the financial crisis, and they conclude that CDX tranches are overpriced relative to index options. ${ }^{3}$ Driessen, Maenhout, and Vilkov (2009), Carr and Wu (2009) and Schurhoff and Ziegler (2011) study prices of index versus individual options. Typically, index options are considered expensive because their prices consistently exceed values implied by standard models (Bondarenko, 2003). Driessen, Maenhout, and Vilkov (2009) argue that this is because index options provide a valuable hedge against increases in correlation, while individual name options do not possess this feature. We find that index put options in the financial sector are different. They are always less expensive than those for other sectors, and they become especially cheap during the crisis.

The rest of the paper is organized as follows. After defining index and basket put and call spreads and their relationship in Section 2, we document their empirical behavior in the financial sector and in all other non-financial sectors in Section 3. Section 4 corrects the basket-index spread for changes in volatility with the help of a simple Black-Scholes model. Section 5 introduces a bailout guarantee into Black-Scholes, and shows that this model helps account for the observed basket-index spread dynamics. Section 6 finds direct evidence for our collective government guarantee hypothesis in the events of the 2007-2009 crisis. Section 7 studies and rules out potential alternative explanations, including counterparty risk, mispricing, short sales constraints, hedging costs and liquidity. The last section concludes. Technical details are relegated to a separate appendix.

\section{Sector Insurance}

Equity options markets are especially well-suited to gauge the market's perception of too-systemicto-fail guarantees. Since guarantees only kick in during a financial crisis, their effect should be most visible in the prices of assets that mostly reflect tail risk, like put options. One may insure against a common financial sector crash by buying puts on each individual financial institution, or by buying a put on the financial sector index. In this section we propose a comparison of these insurance schemes that is useful for identifying investor perceptions of government guarantees.

We focus on a traded sector index $i$ comprised of different stocks $j . S_{i, j}$ and $s_{i, j}$ are the price per share and number of shares outstanding, respectively, for stock $j$ in index $i$. The dollar cost

\footnotetext{
${ }^{3}$ Note that a comparison of single-name CDS and the CDX index (modulo changes in the index composition through defaults) is different because the cost of a basket of credit default swaps has to be equal to the CDX index to rule out arbitrage opportunities.
} 
of the index, i.e., the total market cap of all the firms in the index, is given by $\sum_{j=1}^{N_{i}} s_{i, j} S_{i, j}$, while the price level of the index, $S_{i}$, is a constant fraction $1 /$ scale $_{i}$ of the total index market cap (thus scale $\left._{i}=\sum_{j=1}^{N_{i}} s_{i, j} S_{i, j} / S_{i}\right)$. We use Put basket to denote the price of a basket of put options on all stocks: $P u t_{i}^{b a s k e t}=\sum_{j=1}^{N_{i}} s_{i, j} P u t_{i, j}$. We use $P u t_{i}^{i n d e x}$ to denote the price of a put option on the sector index (similarly for calls).

The basket of put options provides insurance against both common and idiosyncratic stock price crashes, while the index put option only insures states of the world that prompt a common crash. The difference between the costs of these insurance schemes is informative about the relative importance of aggregate and idiosyncratic risks, and is also informative about sector-wide government guarantees.

Strike-Matched Basket To align our comparison between insurance costs, we impose that the total strike price of the two schemes are equal, an approach that we refer to as "strike-matching." To do so, we first choose index strike price $K_{i}$ to match a given $\Delta .{ }^{4}$ Second, we search for options on individual stocks in the index (all of which must share the same $\Delta$, though this may be different from the index $\Delta)$ such that their strike prices $K_{i, j}\left(j=1,2, \ldots, N_{i}\right)$ satisfy

$$
\text { scale }_{i} K_{i}=\sum_{j=1}^{N_{i}} s_{i, j} K_{i, j}
$$

The strike price of the index (in dollars) equals the share-weighted sum of the individual strike prices as in Equation (4).

With strike-matching, the cost of the basket has to exceed the cost of the index option by no arbitrage, which bounds the basket-index spread below from zero. The payoffs at maturity satisfy the following inequality:

$$
\sum_{j=1}^{N_{i}} s_{i, j} \max \left(K_{i, j}-S_{i, j}^{T}, 0\right) \geq \max \left(\text { scale }_{i} K_{i}-\sum_{j=1}^{N_{i}} s_{i, j} S_{i, j}^{T}, 0\right) .
$$

First note that, for each $j, s_{i, j} \max \left(K_{i, j}-S_{i, j}^{T}, 0\right) \geq s_{i, j}\left(K_{i, j}-S_{i, j}^{T}\right)$. This implies that $\sum_{j=1}^{N_{i}} s_{i, j} \max \left(K_{i, j}-\right.$ $\left.S_{i, j}^{T}, 0\right) \geq \operatorname{scale}_{i} K_{i}-\sum_{j=1}^{N_{i}} s_{i, j} S_{i, j}^{T}$. This also means that $\sum_{j=1}^{N_{i}} s_{i, j} \max \left(K_{i, j}-S_{i, j}^{T}, 0\right) \geq \max \left(\operatorname{scale}_{i} K_{i}-\right.$ $\left.\sum_{j=1}^{N_{i}} s_{i, j} S_{i, j}^{T}, 0\right)$, because the left hand side is non-negative. Since the payoff from the option basket exceeds that of the index option, its cost must be weakly higher as well.

We also note that the $\Delta$ of the index option can differ slightly from the moneyness of the option

\footnotetext{
${ }^{4}$ The $\Delta$ of an option is the derivative of the option price with respect to the underlying asset price. While put options have negative $\Delta$, we use the convention of taking the absolute value, so that all $\Delta$ s are positive. $\Delta$ measures the moneyness of an option, with low values such as 20 indicating out-of-the-money options and high values such as 80 indicating in-the-money options. Short-dated at-the-money forward options have a $\Delta$ of approximately 50.
} 
basket. In Appendix B, we consider an alternative method for constructing the basket that uses index and individual options that all have the same moneyness, hence the $\Delta$ is equalized across the two insurance schemes. As results in the appendix show, the conclusions from spreads based on either matching scheme are identical. ${ }^{5}$

Cost Per Dollar Insured To compare prices across time, sectors, and between puts and calls, we define the cost per dollar insured as the price of an option position divided by the dollar amount that it insures. We then define the basket-index put spread as the difference in the per dollar costs of basket and index insurance:

$$
P u t_{i}^{\text {spread }}=\frac{\text { Put } t_{i}^{\text {basket }}}{\sum_{j=1}^{N_{i}} s_{i, j} K_{i, j}}-\frac{\text { scale }_{i} \times P u t_{i}^{\text {index }}}{\sum_{j=1}^{N_{i}} s_{i, j} K_{i, j}} .
$$

Call spreads are defined analogously.

\section{Measuring the Basket-Index Spread}

This section describes the behavior of basket-index option spreads observed in the data. We find that OTM put options on the index were cheap during the financial crisis relative to the individual stock options, while OTM index calls were relatively expensive. This pattern is much more pronounced for the financial sector than for non-financial sectors.

\subsection{Data}

We use daily option data from January 1, 2003 until June 30, 2009. This includes option prices on the nine S\&P 500 sector index exchange-traded funds (ETFs) traded on the CBOE. ${ }^{6}$ As ETFs trade like stocks, options on these products are similar to options on an individual stock. The nine sector ETFs conveniently have no overlap and collectively span the entire S\&P 500. Appendix A contains more details and lists the top 40 holdings in the financial sector ETF. ${ }^{7}$ We also use individual option data for all members of the S\&P 500. The OptionMetrics Volatility Surface provides daily European put and call option prices that have been interpolated over a grid of time-to-maturity

\footnotetext{
${ }^{5}$ We also compare index and basket put prices using options positions that share the same sensitivity to changes in stock return volatility (the so called option "vega"). With the vega-matched approach, spreads between index and basket put prices widen even more for financials versus non-financials compared to the strike-matched results reported below. Detailed estimates from our vega-matched put price comparison are available upon request.

${ }^{6}$ We use SPDR ETFs. SPDRs are a large ETF family traded in the United States, Europe, and Asia-Pacific and managed by State Street Global Advisors. Options on SPDR sector ETFs are physically settled and have an American-style exercise feature.

${ }^{7}$ Our sample length is constrained by the availability of ETF option data. For the financial sector (but not for all non-financial sectors), we are able to go back to January 1999. The properties of our main object of interest, the basket-index put spread for financials, do not materially change if we start in 1999.
} 
$(T T M)$ and option $\Delta$, and that are adjusted to account for the American option feature of the raw option data. ${ }^{8}$ These constant maturity and constant moneyness options are available at various intervals between 30 and 730 days to maturity and at values of (absolute) $\Delta$ ranging from 20 to 80. We focus primarily on options with 365 days to maturity and $\Delta$ of 20 . Implied volatility data are from the interpolated implied volatility surface of OptionMetrics. We use CRSP for returns, market cap, and number of shares outstanding for sector ETFs and individual stocks. We calculate realized volatility of index and individual stock returns, as well as realized correlations between individual stocks. All of our calculations track the varying composition of the S\&P 500 index (as well as the sector indices) to maintain consistency between the composition of the option basket and the index option each day. ${ }^{9}$

\subsection{Main Facts}

Panel I in Table I provides summary statistics for the basket-index spread, in cents per dollar insured, using the strike-matched approach with $\Delta=20$ and $T T M=365$. The first two columns report results for the financial sector. Columns three and four report results for a value-weighted average of the eight non-financial sectors. The last two columns report the differences in the spread between the financial and non-financial sectors. An increase in the spread between the basket and the index means index options become cheaper relative to the individual options. We report statistics for three samples: The entire January 2003 to June 2009 sample, the January 2003 to July 2007 pre-crisis sample, and the August 2007 to June 2009 crisis sample.

Over the pre-crisis sample, the mean spread for OTM puts is 1.7 cents per dollar in the financial sector, and 2.3 cents in the non-financial sectors. During the crisis, the mean put spread is 5.9 cents per dollar for financials and 3.7 cents for non-financials. While there is an across-the-board increase in the put spread from pre-crisis to crisis, the increase is much more pronounced for financials (3.4 times versus 1.6 times). The largest basket-index put spread for financials is 15.9 cents per dollar, recorded on March 6, 2009. It represents $60 \%$ of the cost of the index option on that day. On that same day, the difference between the spread for financials and non-financials peaks at 10.2 cents per dollar insured. Prior to the crisis, the put spread for financials never exceeds 3.8 cents on the dollar, and it never exceed the non-financial put spread by more that 0.4 cents.

Across the entire sample and all sectors, the average basket-index spread for OTM calls is smaller than for puts: 1.0 cents for financials and 2.0 cents for non-financials. OTM call spreads rise slightly in the crisis, reaching 1.1 cents on average for financials and 2.3 cents for non-financials.

\footnotetext{
${ }^{8}$ The option price adjustment performed by OptionMetrics converts prices of American options into equivalent European option prices. This allows us to compare them to the European option price formula we later compute in our model.

${ }^{9}$ Our results remain unchanged when we focus on the subset of firms that remain in the financial sector index throughout our sample.
} 
Appendix Table B reports results for our second approach to constructing the basket-index spread in which the $\Delta \mathrm{s}$ of the two insurance schemes are equalized. We see the same pattern as with the strike-matching approach. The time series correlation between these two measures is over 99\%. Basket-index spreads are somewhat larger when we match the share-weighted strike price. This is because strike-matching uses individual options that have slightly higher $\Delta$ than index options used, which increases spreads. The average $\Delta$-matched put spread during the crisis is 3.8 cents per dollar for financials (compared to 5.9 cents in Table I). The maximum spread is 12.5 cents per dollar insured (compared to 15.9). This number represents $70 \%$ of the cost of the index put on March 6, 2009 (compared to 60\%). On that same day, the difference between the put spread for financials and non-financials peaks at 9.1 cents per dollar.

The top panel of Figure 1 plots financial sector put prices for the entire sample. The solid line shows the cost of the basket of put options per dollar insured and the dashed line plots the cost of the financial sector put index. Before the crisis, the put spread (dotted line) is small and essentially constant at less than two cents per dollar. During the crisis, it increases as the index option gradually becomes cheaper relative to the basket of puts. The basket cost occasionally exceeds 30 cents per dollar while the cost of the index put rarely rises above 20 cents.

The bottom panel of Figure 1 plots call option prices and the call spread. During the crisis, the difference between index calls and the basket of individual calls remains unchanged from its pre-crisis level. We find essentially the same results for call spreads in all other sectors.

Figure 2 compares the put spread of financials and non-financials over time (the dotted lines from the previous figure). For non-financials (solid line), the basket-index spread remains very low until October 2008. For financials (dashed line) on the other hand, the put spread starts to widen in August 2007 (the asset-backed commercial paper crisis), spikes in March 2008 (the collapse of Bear Stearns), and then spikes further after the bailouts of Freddie Mac and Fannie Mae and the Lehman Brothers bankruptcy in September 2008. After a decline in November and December of 2008, the basket-index spread peaks a second time with the rescue of AIG in March 2009. The dotted line plots the difference in put spread between the financial sector and non-financial sectors. This difference is positive throughout the crisis, except for a few days in November of 2008. It increases from the summer of 2007 to October 2008, falls until the end of 2008, and increases dramatically from January to March 2009. None of the eight non-financial sectors experiences anywhere near the large run up in put spreads seen in the financial sector.

\subsection{The Effect of Time-To-Maturity}

Panel II of Table I studies the cost of insurance when TTM is 30 days instead of 365 days. As we show later, these shorter maturity option contracts are more liquid. Naturally, all basket-index spreads are smaller for shorter-dated options since option prices increase with TTM. However the 
spread patterns are the same as in Panel I. The average put spread for financials is 1.4 cents per dollar in the crisis, up from 0.4 cents pre-crisis. This represents an increase by a factor of 3.4. Per unit of time (that is, relative to the ratio of the square root of maturities), the put spread increase during the crisis is larger for $T T M=30$ options than for $T T M=365$ options. The 30 day spread reaches a maximum of 4.0 cents on the dollar, or $52 \%$ of the cost of the index option on that day. For non-financials, the put spread increases by a factor of 1.7 (from 0.5 before the crisis to 0.8 cents during the crisis). Call spreads for both financials and non-financials increase during the crisis, by a factor of 1.8 for financials and 1.5 for non-financials.

\subsection{The Effect of Moneyness}

Table II reports the cost of insurance for the basket versus the index as a function of moneyness $(\Delta)$. It follows the format of Table I. Option prices are naturally higher when options are further in-themoney (ITM), and results show that basket-index spreads also increase in moneyness. However, the proportional increase in the basket-index spread from pre-crisis to crisis is larger for OTM put options than for at-the-money (ATM) puts. The put spread increases by a factor of 3.4 for $\Delta=20,3.7$ for $\Delta=30,3.0$ for $\Delta=40$, and 2.6 for $\Delta=50$. For non-financials, the put spread increase during the crisis is far smaller than for financials across moneyness. The difference between financials and non-financials (reported in the last column) during the crisis is much larger for OTM puts $(2.2$ cents per dollar at $\Delta=20$ and 1.0 at $\Delta=50$ ). As a fraction of the average crisis cost per dollar insured for financial sector index puts, the financials minus non-financials put spreads are larger for deep OTM options $(22 \%$ for $\Delta=20$ versus $5 \%$ for $\Delta=50)$. Similarly, the difference in maximum put spread (as a fraction of the financials index crisis maximum) falls from $38 \%$ to $22 \%$ as moneyness increases from $\Delta=20$ to $\Delta=50$.

\subsection{Bid-Ask Spreads of Options}

To ensure that the increase in the basket-index put spread is not solely due to wider bid-ask spreads during the crisis, we reconstruct an alternative basket-index spread series using raw option price quotes rather than the interpolated volatility surface provided by OptionMetrics. This also serves as a check that OptionMetrics interpolated prices do not suffer from inaccurate extrapolation or reliance on illiquid contracts. To summarize, results from raw options data combined with accounting for bid-ask spreads and contract liquidity generates put spreads that are qualitatively identical, and quantitatively very similar, to the results we reported above.

For this analysis, we construct synthetic options with constant maturity (365 days) and constant $\Delta$ (30) by interpolating raw option prices in a similar vein as OptionMetrics. There are two key differences with the OptionMetrics methodology that makes our approach particularly robust. First, we restrict the universe of raw options to those with positive open interest in order to ensure a 
minimum degree of liquidity. ${ }^{10}$ Second, when constructing synthetic options with constant maturity and constant $\Delta$, we strictly interpolate and never extrapolate. In particular, we require at least one option with $\Delta$ above 30 and one with $\Delta$ below 30, and similarly require one option with maturity greater than 365 and one with maturity less than 365. Often a stock has only one option near $\Delta=20$, which is why we construct synthetic options with $\Delta=30$. Finally, to account for bid-ask spreads, all individual option prices are set equal to the bid price, and all index option prices are set equal to their ask price. This results in the most conservative spread in prices of index puts versus the basket of individual puts, so that the bid-ask-adjusted put spread is always narrower than the spread calculated from midquotes.

The resulting "net of transaction costs" basket-index put spread has very similar behavior to the $\Delta=20$ and TTM $=365$ spread series documented above. Their correlation is $96 \%(0.93 \%)$ over the entire (crisis) sample. The "net of transaction costs" put spread for financials is 1.1 cents per dollar before the crisis, rising to 3.5 cents during the crisis. For non-financial, the spread goes from 1.7 to 2.1 cents. The result is an additional increase of two cents per dollar for financials relative to non-financials, quantitatively consistent with the 2.7 cents estimate presented earlier.

\subsection{Sector Analysis}

Table III compares the basket-index spread for all nine sectors of the S\&P 500. The only other industries which experience significant increases in the basket-index spreads during the crisis are the consumer discretionary sector and the materials sector. Major components of this sector are car manufacturers (Ford and GM) and parts suppliers (e.g., Goodyear and Johnson Controls). This sector also includes retail, home construction (e.g., D. R. Horton and KB Home), hotels (e.g., Marriott and Harrah's) and other businesses with substantial direct and indirect real estate exposure. ${ }^{11}$ The basket-index spread peaks at 12.4 cents per dollar insured for this industry, increasing from an a pre-crisis average of 2.9 cents per dollar insured to 5.1 (rising by a factor of 1.8 over the pre-crisis level, versus a factor of 3.4 for financials). It is conceivable that this sector benefits more than other non-financial sectors when the collective guarantee for the financial sector kicks in. The auto industry also benefited directly from a federal government bailout in fourth quarter of 2008. The materials sector ETF has similarly large exposure to businesses benefitting from government guarantees. Examples include US Steel, whose large customers include the automotive and construction industries, and Weyerhaeuser, which produces building materials and operates a large real estate development segment.

\footnotetext{
${ }^{10}$ Results are similar if we instead require that contracts have positive volume.

${ }^{11}$ Discretionary spending of U.S. consumers experienced the largest post-war decrease during the last quarter of 2008.
} 


\subsection{Bending the Implied Volatility Skew}

Another indicator of the relative costs of index and basket insurance on the financial sector is the difference in their implied volatility skew (the plot of option implied volatilities as a function of option moneyness). The top panel of Figure 3 shows the difference between the implied volatility skew for the financial sector put basket and the index put. During the crisis (circles), the difference between the implied volatility of the basket and that of the index reaches a maximum of $11.5 \%$ for $\Delta=20$, and gradually decreases to $9 \%$ for $\Delta=50$. This evidence is consistent with the presence of a government guarantee which effectively flattens the implied volatility skew for index put options much more than for individual options in the financial sector. Intuitively, this downward sloping pattern arises because a government guarantee has a larger relative impact on index put prices with lower strike prices. In the pre-crisis sample (squares), the basket-index skew spread was flat across moneyness. The same flat shape appears for the basket-index skew spread in non-financial sectors, both pre-crisis (diamonds) and during the crisis (stars). Finally, the bottom panel of Figure 3 plots the implied volatility skew spread inferred from calls. Here we see the exact opposite pattern. During the crisis, the financial sector basket-index skew spread for calls actually has a positive slope (circles). This is because OTM index call options were substantially more expensive and therefore closer to the price of the basket of calls, while the prices of ATM index calls were much further from the basket price. This is consistent with observed elevated return correlations, and what we would expect to see (including for puts) in the absence of a bailout guarantee.

In the options literature, the variance risk premium, which differences implied variances against a realized variance benchmark, offers yet another evaluation of the relative expense of an option position (Carr and Wu, 2009). When implied volatilities are high relative to realized volatilities, the option is expensive relative to the riskiness of the underlying. For financials, the variance risk premium fell from 0.02 before the crisis to -0.20 during the crisis, providing a further indication that the relative value of financial index puts fell over this time. For non-financials, the variance risk premium increases slightly during the crisis. ${ }^{12}$

Similarly, the difference between implied and realized volatility is useful in assessing how price levels of financial and non-financial sector indices affect the put spread. On the first trading day of 2007, the share price of the financials sector ETF and the value-weighted average price of the eight non-financial sector ETFs were roughly equal at $\$ 36.92$ and $\$ 36.40$. By March 2009 , the financial sector had reached as low as $\$ 6.18$ per share, while the non-financial fell as low as $\$ 19.26$. Figure 4 compares daily Black-Scholes implied volatilities minus realized volatilities for the financial and non-financial indices versus the index price level. These data are broken out for the pre-crisis and

\footnotetext{
${ }^{12}$ In order to align realized variance with the forward-looking nature of one year implied variance, we calculate realized variance using a forward-looking 252-day rolling variance of daily returns on the underlying. Our estimated effects on the variance risk premium are quantitatively robust to using backward looking rolling windows and shorter window lengths.
} 
crisis periods, and best fit lines are estimated for each subsample. In the pre-crisis period, the relation of implied minus realized volatility to the index level is similar across sectors. The slope of the best fit line for financials is -0.002 , similar to -0.001 for non-financials. During the crisis, however, the best fit slope for financials rises to 0.015, while the non-financials slope becomes 0.004. The relatively low implied volatility for financials in the second plot suggests that financial sector index puts were particularly cheap during the crisis. The best fit slope of the non-financials, which is substantially shallower than that of financials during the crisis, further suggests that this fact cannot be explained by differences in prices of the underlyings during the crisis.

\section{A Benchmark Model Without Guarantees}

In this section, we consider the possibility that the dramatic increase in volatilities and correlations during the crisis may differentially affect individual and index options, leading in and of itself to an increase in the basket-index put spread. We work from a simple Gaussian option pricing model that we interpret as a counterfactual. It quantifies how observed changes in risks would affect the put spread in the absence of a government guarantee, under the simplifying assumption that returns follow a one-factor Gaussian process. Comparing realized put spreads against a model-based counterfactual allows us to decompose the data into two parts: The portion of spreads explainable by a standard Black and Scholes (1973) (henceforth BS) model, and the residual portion that may be interpreted as a non-Gaussian skewness effect. While it is well known that the BS model does not accurately price index options (Bondarenko, 2003; Pan, 2002), it is nevertheless an interesting lens through which to study the basket-index spread data, in the same tradition as using BS to study implied volatilities. We conclude that this simple model can only explain a small portion of the spread run up that we identify.

\subsection{Single-Factor Model}

We use a simple single-factor model to price options, similar to the one used by Vasicek (2002) to value loan portfolios. The log of the stock return on an individual stock follows:

$$
r^{i n d i v}=\mu-\lambda J^{a}+\sigma_{d} \epsilon
$$

where the shock $\epsilon$ is an idiosyncratic shock which is standard normally distributed and i.i.d. over time and across firms. $J^{a}$ is a sector-wide shock, also i.i.d. and normally distributed: $J^{a} \sim$ $\mathcal{N}\left(0, \delta_{r}^{2}\right)$. We assume that the index is composed of ex-ante identical firms. To account for sector concentration, we choose the number of stand-in firms in sector $i, N_{t}^{i}$, to match the observed inverse Herfindahl of value weights $\omega_{j, i, t}$ for firm $j$ in sector index $i$ on day $t: N_{t}^{i}=\left(\sum_{j} \omega_{j, i, t}^{2}\right)^{-1}$. We use 
$\sigma_{t, i}^{\text {index }}$ to denote the day $t$ volatility of the index return in sector $i$. The volatility of the index is related to the volatility of the stand-in firm, $\sigma_{t, i}^{\text {indiv }}$, according to

$$
\sigma_{t, i}^{\text {index }}=\sqrt{\frac{N_{t}+N_{t}\left(N_{t}-1\right) \rho_{t, i}}{N_{t}^{2}}} \sigma_{t, i}^{i n d i v},
$$

where $\rho_{t, i}$ is an estimate of the return correlation between individual firms in sector $i$.

As when we constructed the empirical spread, we choose index options with $\Delta=20$ (yielding strike price $K_{t}$ ). The same $K_{t}$ is in turn used for the individual option. We then feed in a daily risk-free rate $r_{t}$, the strike $K_{t}$, and estimates of index volatility $\sigma_{t, i}^{\text {index }}$ and individual stock volatility $\sigma_{t, i}^{i n d i v}$ to compute BS prices for the index option and the basket of options with maturity $T$ equal to one year: ${ }^{13}$

$$
P u t_{t, i}^{B S, \text { index }}=B S\left(\sigma_{t, i}^{\text {index }}, K_{t}, r_{t}, T\right), \text { and } P u t_{t, i}^{B S, \text { basket }}=B S\left(\sigma_{t, i}^{\text {indiv }}, K_{t}, r_{t}, T\right) .
$$

The BS basket-index put spread, in cost per dollar insured, is $\left(P u t_{t, i}^{B S, \text { basket }}-P u t_{t, i}^{B S, \text { index }}\right) / K_{t}$. The analysis for call options is analogous. ${ }^{14}$

\subsection{Model-Based Spreads}

We first calculate BS model-implied basket-index spreads for $\Delta=20$ puts. Our goal is to determine if the Black-Scholes model can account for the increase in put spreads during the crisis, once we control for observed increases in individual and index volatility. To estimate index volatility, we use the daily series of BS implied volatilities for the index option, $\sigma_{t, i}^{\text {index}}$, which provides a close match of the financial index put price by construction. To arrive at an estimate of individual option volatilities, we use the daily sequence of realized correlations, $\rho_{t, i}$, together with the index (implied) volatility in Equation (1). ${ }^{15}$ From these inputs, Equation (2) delivers a BS index and basket put option price. We follow the same procedure for the non-financial sectors, as well as for call options.

Table IV reports Black-Scholes put prices, taking into account the estimated volatility and correlation dynamics. The left half of the table shows results for financials, the right half shows non-financials. Side-by-side we report the BS value and the observed value of the index option (columns 1 and 2), the basket (columns 3 and 4), and the basket-index spread (columns 5 and 6). Column 7 reports the difference between the basket-index spread in the data, and the spread

\footnotetext{
${ }^{13}$ We use the yield curve provided by OptionMetrics to estimate the interest rate $r$ for maturity $T$.

${ }^{14}$ The model-implied spreads described here use a strike-matching procedure, just as in Section 3.

${ }^{15}$ Daily pairwise conditional correlations for stocks are estimated using the exponential smoother with smoothing parameter 0.95. Pairwise correlations within the sector are then averaged each day, weighted by the pairs' combined market equity.
} 
generated by the Black-Scholes model.

The model fails to match the sharp increase in the price of the basket in the crisis. In the data, the financial sector put spread increases by a factor of 3.4 (from 1.7 cents per dollar to 5.9), while in the BS model in only increases by a factor of 1.2 (from 3.5 cents to 4.1). This is because BS overprices the basket by 1.8 cents per dollar before the crisis, and underprices it by 1.8 cents during the crisis. Said differently, the volatility level effect contributes only 0.6 cents to the 4.2 cent (per dollar insured) increase in the put spread. The maximum spread conveys the same message: In the data it reaches 15.9 cents, while the maximum BS spread is only 8.1 cents. The trough-to-peak swing in basket-index spreads is about 7 cents in the BS model and more than 14 cents in the data.

The right half of Table IV shows the results for non-financials. During the crisis, the BS put spread falls slightly (column 5), compared to a modest increase in the data (column 6). In the full sample and in each subsample, the difference between the observed put spread for non-financials and its BS-implied value is negative (column 7), and more negative than in the financial sector. This means that non-financial index puts are uniformly more expensive than financial index puts even after controlling for the relative price of a basket of puts, and after controlling for risk differences in a standard one-factor model. The last column of Table IV reports a difference-in-differences number, simultaneously differencing the basket and the index, financials versus non-financials, and data versus Black-Scholes. On average, financial index put options are 2.2 cents per dollar cheaper during the crisis and 0.3 cents cheaper before the crisis than the non-financial index after this multi-dimensional comparison. The maximum financial index put discount is 7.8 cents per dollar during the crisis and 3.4 before the crisis.

Figure 5 plots the difference between the actual and BS-implied spread for the put options on financials (dashed line) and non-financials (solid line). The dotted line plots the difference. The plot shows that the gap between the put spread in the data and BS for financials consistently exceeds that of non-financials, even before the crisis. This implies that financial index puts are consistently cheap relative to both BS and non-financials. In sum, the run up in financial sector put spreads during the crisis cannot be explained in the standard framework. ${ }^{16}$

\subsection{Black-Scholes Implied Correlations}

The increase in put spreads during the crisis is puzzling when viewed alongside the concurrent spike in correlations among financial firms. The single-factor Black-Scholes framework allows us to examine this point in more detail. Instead of evaluating model put spreads at values of realized

\footnotetext{
${ }^{16}$ Our analysis of Black-Scholes model-implied put spreads, as well as the implied correlation analysis below, proxy for index volatility using option-implied volatilities from OptionMetrics. In robustness, we consider instead proxying for volatility using forecasts under the physical measure. In particular, we repeat these analyses using GARCH volatility forecasts and realized rolling volatilities. In both cases, our conclusions remain unchanged: the BS model has tremendous difficulty accounting for the increase in the basket-index put spread observed in the data.
} 
correlation, we may instead invert the put spread formula to back out daily implied correlations $\rho_{t, i}$, given observed index volatility and put spreads (along with Equation (1)). As above, index volatility is proxied with observed implied volatilities. The resulting option-implied correlations are a normalized comparison of the prices on the basket of options and the index option. High implied correlations, compared to realized correlations, indicate that index options are relatively expensive.

Table V reports realized correlations calculated from stock returns, model-implied correlations, and their difference. Prior to the crisis, implied correlations from OTM puts in the financial sector are 19 percentage points higher than actual correlations. During the crisis, the realized correlation increases by 20 percentage points, while model-implied correlations fall by seven percentage points. In other words, when we translate the observed put spread series into implied correlations, their behavior is exactly counter to crisis correlations observed in the data. This anomaly is unique to financial sector puts. For puts in non-financial sectors, and for calls in all sectors, implied and realized correlations both rise during the crisis. ${ }^{17}$

\subsection{Too-Big-To-Fail: Largest Banks}

According to the too-systemic-to-fail hypothesis, some banks are so large and interconnected that their failure may lead to economic disaster. In this spirit, heterogeneity in systemic risk can lead to some banks having higher bailout likelihoods than others. We find evidence that government guarantees primarily benefit large banks, consistent with the the too-systemic-to-fail hypothesis. We focus on a group of 12 large banks that include the ten largest U.S. financial institutions by market cap at the onset of the crisis, plus Fannie Mae and Freddie Mac. This group accounted for over half the market cap of the sector index in July 2007. For each of these financial institutions, we estimate individual return volatility each day as a one year rolling window of daily return volatility. We then use the one-factor Black-Scholes model of Section 4.1 to compute their put option prices. Table VI reports put prices for the largest banks. The first column reports the BS-adjusted cost of the basket of all financials (about 90 firms) as a reference point. The second column reports BS-adjusted prices for the basket of puts consisting of only the 12 largest banks. Remaining columns break out the difference between the actual and BS-implied put prices for each large bank. Prior to the crisis, large banks' OTM put options are 0.4 cents per dollar cheaper than the sector average, after adjusting for volatility effects via BS. This difference rises sixfold during the crisis, as large banks become 2.8 cents per dollar cheaper than the full sector average. While BS-adjusted put option prices increase during the crisis for the average bank stock, they decrease

\footnotetext{
${ }^{17}$ Results are nearly identical for short-dated options with $T T M$ of 30 days. We omit this analysis in the interest of space.
} 
for the largest banks. This striking conclusion holds for nine out of the 12 banks. ${ }^{18}$

\section{Benchmark Model with a Government Guarantee}

The previous sections show a large increase in the basket-index put spread for financials relative to non-financials and show that this spread was not accounted for by volatility dynamics. In this section, we show that observed basket-index put spread dynamics can be accounted for by a simple option pricing model, once a collective government guarantee is assumed. This provides indirect evidence for our hypothesis that the government played an important role in generating observed spread patterns. In Section 6 we provide direct evidence based on an event study of government announcements.

We extend the simple single-factor model developed in Section 4 and assume that the maximum sector-wide loss rate tolerated by the government is fixed (and common knowledge). While the resulting model still faces substantial challenges in accounting for the level of individual and index option prices, as one might expect from a Black-Scholes type model, it is the simplest model to illustrate the effect of collective bailout guarantees. ${ }^{19}$

Log stock returns for the stand-in individual stock follow the same process as in Section 4 with the following exception. The single sector-wide shock is truncated by a government guarantee. This truncation occurs at $\underline{J}<\infty$, and modifies the sector-wide shock as

$$
J^{a}=\min \left(J^{r}, \underline{J}\right), \quad J^{r} \sim \mathcal{N}\left(0, \delta_{r}^{2}\right) .
$$

We derive a closed-form expression for the bailout-adjusted index put and basket put prices:

$$
P u t_{t, i}^{\text {Bail,index }}=B S^{\text {Bail }}\left(\sigma_{t, i}^{\text {index }}, K_{t}, r_{t}, T, \mu_{t, i}, \underline{J}\right) \text {, and } P u t_{t, i}^{\text {Bail,basket }}=B S^{\text {Bail }}\left(\sigma_{t, i}^{\text {indiv }}, K_{t}, r_{t}, T, \mu_{t, i}, \underline{J}\right) \text {. }
$$

Appendix D contains the derivation of the put option prices; it relies on results in Appendix $\mathrm{C}$ and on auxiliary lemmas stated in Appendix F. Bailout-adjusted option prices depend on two additional parameters: (i) $\underline{J}$ is the maximum loss tolerated by the government and (ii) $\mu_{t, i}$ is the expected return on the stocks in sector $i$. The strike-matched Black-Scholes basket-index spread is defined as before.

\footnotetext{
${ }^{18}$ Two of the three for which BS-adjusted option prices rise are Freddie Mac and Freddie Mae, which actually fail in September 2008. This failure wiped out the equity holders, and the rise in their put prices during the crisis (in this case August 2007-September 2008) reflects the increased probability of a collapse.

${ }^{19}$ The NBER working paper version of this paper considers a model with disasters that accurately matches both option pricing levels and the basket-index spread, but only once a bailout guarantee is introduced. That model requires several auxiliary assumptions which we avoid in the simplified model here.
} 


\subsection{Model-Based Spreads with a Government Guarantee}

To compute the basket-index spread in the presence of a bailout, we follow the same procedure that we described in Section 4. We feed in option-implied index volatility and realized correlations and use Equation (1) to obtain the stand-in firm's volatility. We also need an estimate of the expected return $\mu_{t, i}$. To obtain a model-free, option-based estimate for the expected return (in levels), we use the simple variance swap of idea of Martin (2011). ${ }^{20}$ Appendix E discusses the details and shows how expected returns, volatilities, and correlations relate to the structural parameters of the model. The model delivers a daily put price for the basket and the index via Equation (3).

The solid line in Figure 6 plots the basket-index spread in the bailout model (with $\underline{J}=0.60$ ) against the observed basket-index spread (dashed line). The key result is that the model-implied spread closely tracks the spread in the data once a bailout is embedded in the standard model. The correlation between the two is $81 \%(0.86 \%)$ over the entire (crisis) sample. The bailout-adjusted spread from the model peaks at 16.3 cents per dollar insured, versus 15.9 in the data (strikematched). The dotted line plots the difference in put spreads from the models with and without a bailout guarantee. The correlation between this difference and the put spread in the data is $67 \%$ over the entire sample ( $62 \%$ during crisis). While the bailout model misses part of the initial run-up in the basket-index spread after March 2008, it does a remarkable job of explaining the remaining variation.

Table VII reports the basket-index put spread for the bailout model for different values of the guarantee threshold $\underline{J}$, and compares it to the data. The top panel is for financials, the bottom panel for non-financials. The put spreads in both the data and the bailout model are differenced against put spreads from the no-bailout Black-Scholes model. A lower value for $\underline{J}$ makes the government guarantee stronger and eliminates more of the aggregate downside risk. The column $\underline{J}=\infty$ recovers the original bailout-free BS model. The effect of $\underline{J}$ on the put spread is nonmonotonic since the price of sector-wide risk has to increase to match the risk premium, which starts to lower the basket-index spread as the bailout becomes weaker (that is, when $\underline{J}$ is large). Prior to the crisis, the average put spread in the data (in deviation from Black-Scholes) is -1.8 cents. At pre-crisis risk levels, the bailout model struggles to generate much difference with the no-bailout model for most values of $\underline{J}$, and hence fails to account for the fact that index put options are relatively expensive in normal times. The real test for the bailout mechanism is the crisis sample. When we choose the maximum loss to be $\underline{J}$ of 0.60 (which implies a maximum loss rate of $51 \%$ in levels), the model delivers a BS-adjusted spread of 1.5 cents per dollar, close to the

\footnotetext{
${ }^{20}$ Martin (2011) derives a model free notion of implied volatility, SVIX, from an equally weighted average of put and call prices at different strikes. He uses $S V I X$ to derive a lower bound on the expected risk premium under weak assumptions. To implement our empirics, we assume the lower bound is satisfied with equality. We separately compute $S V I X$ for financials and for the non-financial sectors. Note that, since it is based on options data, our expected return estimate reflects all potential effects of sector-wide guarantees on stock returns. This makes the empirical quantity directly comparable to the theoretical expected return entering the put price formula.
} 
1.8 cents in the data. The maximum spread is 8.1 cents per dollar, again close to the 9.3 cents in the data.

Panel II of Table VII shows that the effects of a similar-size guarantee are much smaller for nonfinancials. While the increase in the BS-adjusted put spread is small in the data (1.3 cents), it is smaller still in the model $(0.1$ cents when $\underline{J}=0.60)$. There is not enough volatility in non-financial stock returns to make the guarantee more valuable. ${ }^{21}$

For a given maximum loss rate $\underline{J}$, we can estimate the dollar value of the bailout by computing the cost of obtaining downside insurance for the sector (using index options) with and without the bailout guarantee. The difference is our estimate of the total value of the bailout guarantee. Holding fixed $\underline{J}=0.60$, the average crisis value of the bailout is $\$ 42.38$ bn, compared to $\$ 0.63$ bn before the crisis. At its peak, the guarantee to equityholders of the financial sector is valued at nearly $\$ 160$ bn.

\section{Government Announcements}

In this section, we provide direct evidence that the dynamics of the basket-index spread during the crisis are closely tied to government policy announcements. Under the collective bailout hypothesis, an increase in the probability of a financial disaster increases the basket-index put spread. To link the put spread directly to (the market's perceptions of) the government intervention, we study policy announcements during the financial crisis of 2007-2009. We focus on significant announcements for which we can determine the ex-ante sign of the effect on the likelihood (and size) of a collective bailout. Our evidence suggests that put spreads respond to government announcements in a manner consistent with the collective bailout hypothesis. For this analysis we focus on BS-adjusted basket-index spreads, thus the results are not simply picking up volatility effects.

We identify six events that increase the probability of a government bailout for shareholders of the financial sector: (i) July 11, 2008: Paulson requests government funds for Fannie Mae and Freddie Mac (ii) October 3, 2008: Revised bailout plan (TARP) passes the U.S. House of Representatives, (iii) October 6, 2008: The Term Auction Facility is increased to $\$ 900 \mathrm{bn}$, (iv) November 25, 2008: The Term Asset-Backed Securities Loan Facility (TALF) is announced, (v) January 16, 2009: Treasury, Federal Reserve, and the FDIC provide assistance to Bank of America, (vi) February 2, 2009: The Federal Reserve announces it is prepared to increase TALF to $\$ 1$ trn. We refer to these as positive announcement dates.

We also identify six negative announcements that (we expect ex-ante to) decrease the probability of a bailout for shareholders: (i) March 3, 2008: Bear Stearns is bought for $\$ 2$ per share, (ii)

\footnotetext{
${ }^{21}$ Rather than using the put option-implied volatility as a measure of index return volatility, we can instead use rolling-window realized volatilities or GARCH-model forecasts to evaluate model-implied spreads, similar to the analysis in Section 4.4. Results are similar to those using implied volatilities.
} 
September 15, 2008: Lehman Brothers files for bankruptcy, (iii) September 29, 2008: House votes no on the bailout plan, (iv) October 14, 2008: Treasury announces $\$ 250 \mathrm{bn}$ capital injections, (v) November 7, 2008: President Bush warns against too much government intervention in the financial sector, and (vi) November 13, 2008: Paulson indicates that TARP will not used for buying troubled assets from banks.

First, we consider the difference-in-differences (data minus Black-Scholes, and basket minus index) around announcement dates. We find that the basket-index spread of financials increases after positive announcement dates relative to the implied Black-Scholes value, and declines after negative announcement dates. Panel I of Figure 7 plots the results. In the five days following a positive announcement we find an average spread increase of 1.6 cents, or $64 \%$. The five days following a negative announcement experience an average spread decrease of 1.3 cents, or $40 \%$. The pre-announcement movements suggest that some announcements may be anticipated by the market.

Second, we look at a triple difference: financials minus non-financials, data minus Black-Scholes, and basket minus index. Panel II of Figure 7 plots these differences around announcement dates. We find that the triple difference increases on average by 0.9 cents, or $28 \%$, in the first five days following a positive announcement, while it decreases 1.9 cents, or $23 \%$, in the five days following a negative announcement.

The largest positive effect occurs after the House approves the Emergency Economic Stabilization Act of 2008 (Public Law 110-343) on October 3, which establishes the $\$ 700$ billion Troubled Asset Relief Program (TARP), raising the spread 47\% in the first five days after the announcement. Furthermore, the approval of TARP started a sustained increase in the basket-index spread in the ensuing period.

The failures of Bear Stearns and Lehman Brothers initially reduce the basket-index put spread. The Lehman failure was then followed by an increase in the spread as the resulting turmoil convinced markets that future bailouts would be more likely. The largest negative effect was registered on October 14, 2008 when the U.S. Treasury announced the TARP would be used as a facility to purchase up to $\$ 250 \mathrm{bn}$ in preferred stock of U.S. financial institutions. The Treasury essentially shifted TARP's focus from purchasing toxic assets to recapitalizing banks. This decision diluted existing shareholders, driving the put spread down by $22 \%$ over the next five days. This was the start of a longer decline in the spread that was reinforced by speeches delivered by president Bush and Secretary Paulson in early November. Clearly, there was a fear that bank shareholders would not receive the government bailout they had hoped for.

This decline in the spread was reversed only in early January 2009 when the FDIC, the Fed and the Treasury provided assistance to Bank of America, without diluting existing shareholders. The put spread started its largest increase in the beginning of February and peaked in March. ${ }^{22}$

\footnotetext{
${ }^{22}$ On February 10, 2009, Treasury Secretary Geithner announced a Financial Stability Plan involving Treasury
} 
Markets were gradually reassured that the government was indeed committed to bailing out the financial sector without wiping out equity holders. Our measure of the value of the bailout guarantee suggests that the market was not initially reassured by the TARP program and its implementation, which consisted mostly of cash infusions from sales of preferred shares. Only when the Treasury and the Federal Reserve explicitly announces programs to purchase toxic assets such as mortgage-backed securities does the collective bailout guarantee become valuable.

\section{Alternative Explanations}

This section consider alternatives to the collective bailout explanation for the behavior of crisis put spreads, including counter-party risk, mispricing, short sale restrictions, hedging costs, and liquidity. We conclude that none are consistent with the patterns in the data.

\subsection{Counterparty Credit Risk}

The most obvious alternative explanation is counterparty risk. OTM financial index put options pay off in states of the world in which the financial system is potentially in a meltdown. If these contracts are not honored in these states of the world, that could generate a basket-index spread increase for put options on financial firms, more so than for other firms.

All of the options traded on the CBOE are cleared by the Options Clearing Corporation (OCC), which also is the ultimate guarantor of these contracts. The writer of an option is subject to margin requirements that exceed the current market value of the contract by a margin that provides a cushion to cover two-day market risk. These margins are exempt from bankruptcy clawbacks. The positions are marked-to-market on a daily basis. During the crisis, there were intra-day margin calls as well. In addition, the OCC has a clearing fund. The size of the clearing fund is directly tied to the volume of transactions. This clearing fund was only tapped once after the crash of 1987 , and the amount was small. The clearing fund was not used during the recent financial crisis, even though the volume of transactions set a new record. S\&P has consistently given the OCC a AAA rating since 1993. So, counterparty risk seems limited.

Moreover, if counter-party credit risk were the driver of the basket-index spread, then the percentage effects should be much larger for shorted-dated options. Given that these contracts are

purchases of convertible preferred stock in eligible banks, the creation of a Public-Private Investment Fund to acquire troubled loans and other assets from financial institutions, expansion of the Federal Reserve's Term AssetBacked Securities Loan Facility (TALF), and new initiatives to stem residential mortgage foreclosures and to support small business lending. The Federal Reserve Board announced that it was prepared to expand TALF to as much as $\$ 1$ trn and to broaden eligible collateral to include AAA-rated commercial mortgage-backed securities, privatelabel residential mortgage-backed securities, and other asset-backed securities. The expansion of TALF would be supported by $\$ 100 \mathrm{bn}$ from TARP. In the last week of February there was discussion of assurances to prop up the banking system, including Fannie Mae and Freddie Mac. 
marked-to-market every day, the effect of counter-party credit risk on a one-year option is of order $\sigma \sqrt{1 / 250}$ rather than $\sigma$, because after one day more margin is posted if the index declines enough during the day, and the contract is collateralized again. However, we find that the basket-index spreads roughly increase with the square root of the maturity of the contract. For example, for the strike-matched index with $\Delta$ of 20 , the average basket-index spread during the crisis is 5.9 cents per dollar at $T T M=365$, while it is 4.7 cents per dollar after multiplying the $T T M=30$ spread by $\sqrt{12}$. If anything, the effect on the basket-index spread for one-year options is larger.

Finally, the dynamics of the basket-index spread around government announcements are inconsistent with a counter-party credit risk explanation. Announcements that increase the likelihood of a bailout increased the basket-index spread, while negative announcements decreased the basketindex spread. The counterparty credit risk explanation would obviously predict the opposite effect. Moreover, it seems hard to argue that the likelihood of a complete meltdown of the financial system was highest in March 2009, when the basket-index spread peaked.

\subsection{Mispricing, Cost of Hedging and Short-Sale Restrictions}

Recent research has documented violations of the law of one price in several segments of financial markets during the crisis. In currency markets, violations of covered interest rate parity have been documented (see Garleanu and Pedersen, 2009). In government bond markets, there was mispricing between TIPS, nominal Treasuries and inflation swaps (see Fleckenstein, Longstaff, and Lustig, 2010). Finally, in corporate bond markets, large arbitrage opportunities opened up between CDS spreads and the CDX index and between corporate bond yields and CDS (see Mitchell and Pulvino, 2009). A few factors make the mispricing explanation a less plausible candidate for our basket-index put spread findings.

First, trading on the difference between the cost of index options and the cost of the basket does not require substantial capital, unlike some of these other trades (CDS basis trade, TIPS/Treasury trade). Hence, instances of mispricing in the options basket-index spread due to capital shortages are less likely to persist (see Mitchell, Pedersen, and Pulvino, 2007; Duffie, 2010).

Second, if we attribute our basket-index spread findings to mispricing, we need to explain the divergence between put and call spreads. This asymmetry rules out most alternative explanations except perhaps counter-party risk (which we address above) and the cost of hedging.

Single name options and index options have different costs of hedging. Single name options are hedged with cash market transactions while index options are hedged using futures since the latter are more liquid. Hedging using cash transactions is more expensive than using futures. This

affects put options more than call options since shorting a stock accrues additional costs, and these costs can be larger in times of crisis. The difference in the cost of hedging should affect financials 
more than other sectors because there were no futures on most other sectors, ${ }^{23}$ and because the difficulty of shorting stocks was concentrated in financials. Therefore the benefit of available futures contracts on the financials index compared to cash trading was bigger than in other sectors.

In fact, there were explicit short sale restrictions on financial sector stocks. A short sale ban could push investors to express their bearish view by buying put options instead of shorting stocks. Market makers or other investors may find writing put options more costly when such positions cannot be hedged by shorting stock. The SEC imposed a short sale ban from September 19, 2008 until October 8, 2008 which affected 800 financial stocks. From July 21, 2008 onwards, there was a ban on naked short-selling for Freddie Mac, Fannie Mae, and 17 large banks. However, exchange and over-the-counter option market makers where exempted from both SEC rules so that they could continue to provide liquidity and hedge their positions during the ban. Both the short window of the ban compared to the period over which the put spread increased and the exemption for market makers make the short sale ban an unlikely explanation for our findings.

We further explore whether put spreads are driven by short sales constraints by comparing the difference in cost of shorting financial and non-financials stocks to the difference in put spreads. To measure short sales costs, we use securities lending fee data from the SEC for each stock in the S\&P 500, and calculate value-weighted average lending fees by sector. ${ }^{24}$ The difference in lending fees between financial and non-financial stocks is plotted in Figure 8 (corresponding to left vertical axis). Alongside the fee difference we also plot the the difference in put spreads (corresponding to right vertical axis). There is little association between the two series: Changes in lending fees only have a $3.2 \%$ correlation with changes in the put spread.

Finally, our analysis of implied volatility on index options has established that these index options are cheap during the crisis even when comparing implied and realized volatility. This comparison does not rely at all on single name option prices.

\subsection{Liquidity}

Another potential alternative explanation of our findings is that index put options are more liquid than individual options, and that their relative liquidity rose during the financial crisis. The same explanation must also apply to call options. We now argue that these liquidity facts are an unlikely explanation for our findings, often pointing in the opposite direction. These findings corroborate our bid-ask spread analysis in Section 3.5.

Table VIII reports summary statistics for the liquidity of put options on the S\&P 500 index,

\footnotetext{
${ }^{23}$ A futures contract on the financial sector (Financial SPCTR futures) was traded on the CME, but not for other sectors.

${ }^{24}$ Lending fees for Citigroup appear driven by an outlier observation from a particular lender for the last half of 2009, thus we omit Citigroup from this average. This anomalous Citigroup data point also bears no association to the behavior of put spreads we document. Including Citigroup in our calculation has no impact on our conclusions regarding lending fees.
} 
sector indices (a value-weighted average across all 9 sectors), the financial sector index, all individual stock options (a value-weighted average), and individual financial stock options. The table reports daily averages of the bid-ask spread in dollars, the bid-ask spread in percentage of the midpoint price, trading volume, and open interest. The columns cover the full range of moneyness, from deep OTM $(\Delta<20)$ to deep ITM $(\Delta>80)$, while the rows report a range of option maturities. We separately report averages for the pre-crisis and crisis periods. It is worth pointing out that a substantial fraction of trade in index options takes place in over-the-counter markets, which are outside our database. Hence, these bid-ask and volume numbers understate the degree of liquidity. However, absent arbitrage opportunities across trading locations, the option prices in our database do reflect this additional liquidity.

Deep OTM put options with $\Delta<20$ have large spreads, and volume is limited. OTM puts with $\Delta$ between 20 and 50 still have substantial option spreads. For long-dated OTM puts (maturity in excess of 180 days), the average pre-crisis spread is $5.5 \%$ for the $\mathrm{S} \& \mathrm{P} 500,12.8 \%$ for the sector options, $10.8 \%$ for the financial sector options, $6.8 \%$ for all individual stock options, and $7.0 \%$ for individual stock options in the financial sector. Financial sector index options appear, if anything, more liquid than other sector index options. The liquidity difference between index and individual put options is smaller for the financial sector than for the average sector.

Furthermore, during the crisis, the liquidity of the options appears to increase. For long-dated OTM puts, the spreads decrease from 5.5\% to 4.7\% for S\&P 500 options, from 12.8 to $7.8 \%$ for sector options, from $10.8 \%$ to $4.5 \%$ for financial sector options, from 6.8 to $5.5 \%$ for all individual options, and from $7.0 \%$ to $5.8 \%$ for financial firms' options. ${ }^{25}$ At the same time, volume and open interest for long-dated OTM puts increased. Volume increased from 400 to 507 contracts for the S\&P 500 index options, from 45 to 169 for the sector options, from 287 to 1049 for financial index options, and from 130 to 162 for individual stock options in the financial sector. During the crisis, trade in OTM financial sector put options invariably exceeds not only trade in the other sector OTM put options but also trade in the OTM S\&P 500 options. The absolute increase in liquidity of financial sector index puts during the crisis and the relative increase versus individual put options suggests that index options should have become more expensive, not cheaper during the crisis.

Short-dated put options (with maturity less than 10 days) are more liquid than long-dated options; they experience a larger increase in trade during the crisis. We verified above that our results are robust across option maturities.

Table IX reports the same liquidity statistics for calls. Calls and puts are similarly liquid yet display very different basket-index spread behavior. Finally, the increase in the basket-index spread during the crisis is also present in shorter-dated options, which are more liquid. All these facts suggest that illiquidity is an unlikely explanation for our findings.

\footnotetext{
${ }^{25}$ Absolute bid-ask spreads increase during the crisis but this is explained by the rise in put prices during the crisis. Absolute bid-ask spreads increase by less than the price.
} 


\section{Conclusion}

We uncover new evidence from option prices that suggests the government absorbs aggregate tail risk by providing a sector-wide bailout guarantee to the financial sector. In doing so, the government subsidizes private insurance against financial sector systemic risk. In turn, this effectively bends down the implied volatility skew for index put options on the financial sector, and causes the spread between the price of financial index puts and a basket of individual bank puts to diverge. These effects are clearly visible in options prices during the 2007-2009 financial crisis.

A simple, single factor model helps us to understand whether fluctuations in the basket-index put spread may be attributed to changing risk exposure, or if something more is needed. The standard model fares poorly in explaining the sharp increase in the financial sector put spread during the crisis. But a modification of the standard model that truncates downside risk in the financial sector does a much better job explaining crisis put spread behavior. These results are consistent with the interpretation that the government provides a collective bailout guarantee to the banking sector. Direct evidence of basket-index spread dynamics around government announcements confirms this interpretation.

\section{References}

Acharya, V. V., L. H. Pedersen, T. Philippon, and M. P. Richardson (2010): "Measuring Systemic Risk," Working Paper NYU Stern.

Adrian, T., And M. K. Brunnermeier (2010): "CoVaR," Federal Reserve Bank of New York Working Paper.

Black, F., And M. Scholes (1973): "The Pricing of Options and Corporate Liabilities," Journal of Political Economy, 81(3), 637-654.

Bond, P., I. Goldstein, And E. S. Prescott (2010): "Market-Based Corrective Actions," Review of Financial Studies, 23(2), 781-820.

Bondarenko, O. (2003): "Why Are Put Options So Expensive?," Working Paper University of Illinois.

Brownless, C., And R. Engle (2010): "Volatility, Correlation and Tails for Systemic Risk Measurement," Working Paper NYU Stern.

Carr, P., And L. Wu (2009): "Variance Risk Premiums," Review of Financial Studies, 22, 1311-1341.

Coval, J., J. Jurek, And E. Stafford (2009): "Economic Catastrophy Bonds," American Economic Review, 99 (3), 628-666, HBS Working Paper.

Driessen, J., P. J. Maenhout, and G. Vilkov (2009): "The Price of Correlation Risk: Evidence from Equity Options," The Journal of Finance, 64(3), 1377-1406. 
Duffie, D. (2010): "Presidential Address: Asset Price Dynamics with Slow-Moving Capital," Journal of Finance, 65(4), 1237-1267.

Fleckenstein, M., F. A. Longstaff, and H. N. Lustig (2010): "Why Does the Treasury Issue Tips? The Tips-Treasury Bond Puzzle," NBER Working Paper, 16538.

Gandhi, P., And H. Lustig (2010): "Size Anomalies in Bank Stock Returns: A Fiscal Explanation," Working Paper UCLA Anderson School of Management.

Garleanu, N., and L. H. Pedersen (2009): "Margin-Based Asset Pricing and Deviations from the Law of One Price," Working Paper Haas School of Business at UCBerkeley.

Huang, X., H. Zhou, And H. Zhu (2011): "Systemic Risk Contributions," Working Paper Federal Reserve Bank.

Lucas, D., And R. McDonald (2010): "Valuing Government Guarantees: Fannie and Freddie Revisited," Measuring and Managing Federal Financial Risk, pp. 131-162.

Lucas, D., And R. L. MCDonald (2006): "An options-based approach to evaluating the risk of Fannie Mae and Freddie Mac," Journal of Monetary Economics, 53(1), 155-176.

Martin, I. (2011): "Simple Variance Swaps," Working Paper Stanford GSB.

Mitchell, M., L. H. Pedersen, and T. Pulvino (2007): "Slow Moving Capital," American Economic Review, 97, 215-220.

Mitchell, M., And T. Pulvino (2009): "Arbitrage crashes and the speed of capital," Working Paper $A Q R$.

O'Hara, M., and W. Shaw (1990): "Deposit Insurance and Wealth Effects: The Value of Being "Too Big to Fail."," Journal of Finance, 45(5), 1587-1600.

PAN, J. (2002): "The jump-risk premia implicit in options: evidence from an integrated time-series study," Journal of Financial Economics, 63(1), 3-50.

Schurhoff, N., And A. Ziegler (2011): "Variance risk, financial intermediation, and the crosssection of expected option returns," Working Paper University of Zurich.

VAsiceK, O. A. (2002): "The distribution of loan portfolio value," Risk, 15, 160.

Veronesi, P., And L. Zingales (2010): "Paulson's gift," Journal of Financial Economics, 97(3), 339-368. 
Table I: Basket-Index Spreads on Out-of-the-Money Options

\begin{tabular}{|c|c|c|c|c|c|c|c|}
\hline & & \multicolumn{2}{|c|}{ Fin. } & \multicolumn{2}{|c|}{ Non-fin. } & \multicolumn{2}{|c|}{ Diff. } \\
\hline & & Puts & Calls & Puts & Calls & Puts & Calls \\
\hline & & \multicolumn{6}{|c|}{ Panel I: $T T M=365$} \\
\hline \multirow[t]{3}{*}{ Full Sample } & mean & 2.94 & 0.99 & 2.69 & 2.02 & 0.25 & -1.03 \\
\hline & std & 2.52 & 0.10 & 1.08 & 0.25 & 1.69 & 0.19 \\
\hline & $\max$ & 15.87 & 1.27 & 7.58 & 2.75 & 10.17 & -0.71 \\
\hline \multirow[t]{3}{*}{ Pre-Crisis } & mean & 1.71 & 0.95 & 2.26 & 1.90 & -0.55 & -0.95 \\
\hline & std & 0.35 & 0.07 & 0.59 & 0.13 & 0.33 & 0.09 \\
\hline & $\max$ & 3.76 & 5.10 & 9.65 & 4.57 & 0.44 & 2.08 \\
\hline \multirow[t]{4}{*}{ Crisis } & mean & 5.85 & 1.08 & 3.70 & 2.31 & 2.15 & -1.23 \\
\hline & std & 3.01 & 0.10 & 1.27 & 0.21 & 2.08 & 0.23 \\
\hline & $\max$ & 15.87 & 1.27 & 7.58 & 2.75 & 10.17 & -0.71 \\
\hline & & \multicolumn{6}{|c|}{ Panel II: $T T M=30$} \\
\hline \multirow[t]{3}{*}{ Full Sample } & mean & 0.68 & 0.43 & 0.58 & 0.56 & 0.11 & -0.13 \\
\hline & std & 0.61 & 0.16 & 0.25 & 0.16 & 0.41 & 0.08 \\
\hline & $\max$ & 3.98 & 1.08 & 1.98 & 1.31 & 2.66 & 0.20 \\
\hline \multirow[t]{3}{*}{ Pre-Crisis } & mean & 0.40 & 0.35 & 0.48 & 0.48 & -0.08 & -0.13 \\
\hline & std & 0.07 & 0.05 & 0.14 & 0.07 & 0.12 & 0.07 \\
\hline & $\max$ & 0.76 & 1.71 & 2.26 & 0.95 & 0.86 & 0.95 \\
\hline \multirow[t]{3}{*}{ Crisis Sample } & mean & 1.36 & 0.62 & 0.81 & 0.74 & 0.55 & -0.13 \\
\hline & std & 0.78 & 0.17 & 0.30 & 0.15 & 0.53 & 0.09 \\
\hline & $\max$ & 3.98 & 1.08 & 1.98 & 1.31 & 2.66 & 0.20 \\
\hline
\end{tabular}

This table reports summary statistics for the basket-index spread in the cost of insurance per dollar insured for financials, non-financials and their difference (financials minus non-financials). Numbers reported are in cents per dollar of strike price. The full sample covers $1 / 2003-6 / 2009$. The pre-crisis sample covers $1 / 2003-7 / 2007$. The crisis sample covers 8/2007-6/2009. $\Delta$ is 20. In the top half of the table, time-to-maturity is 365 days, in the bottom half it is 30 days. Spreads are constructed using strike-matching as described in Section 3. 
Table II: Summary Statistics for Spreads on Options Sorted by Moneyness

\begin{tabular}{|c|c|c|c|c|c|c|c|}
\hline & & \multicolumn{2}{|c|}{ Fin. } & \multicolumn{2}{|c|}{ Non-fin. } & \multicolumn{2}{|c|}{ Diff. } \\
\hline & & Puts & Calls & Puts & Calls & Puts & Calls \\
\hline & & \multicolumn{6}{|c|}{$\Delta=20$} \\
\hline \multirow[t]{2}{*}{ Full } & mean & 2.94 & 0.99 & 2.69 & 2.02 & 0.25 & -1.03 \\
\hline & $\max$ & 15.87 & 1.27 & 7.58 & 2.75 & 10.17 & -0.71 \\
\hline \multirow[t]{2}{*}{ Pre-Crisis } & mean & 1.71 & 0.95 & 2.26 & 1.90 & -0.55 & -0.94 \\
\hline & $\max$ & 3.76 & 1.19 & 4.57 & 2.29 & 0.44 & -0.73 \\
\hline \multirow[t]{3}{*}{ Crisis } & mean & 5.86 & 1.08 & 3.70 & 2.31 & 2.15 & -1.23 \\
\hline & $\max$ & 15.87 & 1.27 & 7.58 & 2.75 & 10.17 & -0.71 \\
\hline & & \multicolumn{6}{|c|}{$\Delta=30$} \\
\hline \multirow[t]{2}{*}{ Full } & mean & 2.13 & 1.49 & 2.53 & 2.59 & -0.39 & -1.10 \\
\hline & $\max$ & 14.09 & 2.00 & 7.36 & 3.56 & 9.54 & -0.47 \\
\hline \multirow[t]{2}{*}{ Pre-Crisis } & mean & 1.19 & 1.44 & 2.16 & 2.44 & -0.97 & -1.00 \\
\hline & $\max$ & 2.45 & 1.86 & 4.01 & 3.00 & 0.66 & -0.71 \\
\hline \multirow[t]{3}{*}{ Crisis } & mean & 4.38 & 1.62 & 3.41 & 2.96 & 0.97 & -1.34 \\
\hline & $\max$ & 14.09 & 2.00 & 7.36 & 3.56 & 9.54 & -0.47 \\
\hline & & \multicolumn{6}{|c|}{$\Delta=40$} \\
\hline \multirow[t]{2}{*}{ Full } & mean & 2.58 & 2.18 & 2.74 & 2.34 & -0.16 & -0.15 \\
\hline & $\max$ & 14.29 & 3.05 & 7.11 & 3.13 & 8.84 & 0.75 \\
\hline \multirow[t]{2}{*}{ Pre-Crisis } & mean & 1.62 & 2.09 & 2.38 & 2.24 & -0.76 & -0.16 \\
\hline & $\max$ & 2.95 & 2.79 & 4.60 & 2.75 & 1.45 & 0.27 \\
\hline \multirow[t]{3}{*}{ Crisis } & mean & 4.87 & 2.41 & 3.60 & 2.56 & 1.27 & -0.14 \\
\hline & $\max$ & 14.29 & 3.05 & 7.11 & 3.13 & 8.84 & 0.75 \\
\hline & & \multicolumn{6}{|c|}{$\Delta=50$} \\
\hline \multirow[t]{2}{*}{ Full } & mean & 3.08 & 1.16 & 3.45 & 2.99 & -0.36 & -1.83 \\
\hline & $\max$ & 15.59 & 2.18 & 8.01 & 4.19 & 9.25 & -0.43 \\
\hline \multirow[t]{2}{*}{ Pre-Crisis } & mean & 2.11 & 1.40 & 3.04 & 2.87 & -0.93 & -1.47 \\
\hline & $\max$ & 4.01 & 2.18 & 5.70 & 3.59 & 1.59 & -0.43 \\
\hline \multirow[t]{2}{*}{ Crisis } & mean & 5.39 & 0.58 & 4.40 & 3.27 & 0.99 & -2.68 \\
\hline & $\max$ & 15.59 & 2.08 & 8.01 & 4.19 & 9.25 & -1.26 \\
\hline
\end{tabular}

This table reports summary statistics for the basket-index spread in the cost of insurance per dollar insured for financials, non-financials and their difference (financials minus non-financials) using strike-matching. Numbers reported are in cents per dollar of strike price. The full sample covers $1 / 2003-6 / 2009$. The pre-crisis sample covers 1/2003-7/2007. The crisis sample covers 8/2007-6/2009. Spreads are constructed using strike-matching as described in Section 3. 
Table III: Basket-Index Spreads on Out-of-the-Money Options in Other Sectors

\begin{tabular}{|c|c|c|c|c|c|}
\hline Sector & & $\begin{array}{c}\text { Full } \\
\text { Sample }\end{array}$ & Pre-Crisis & Crisis & $\begin{array}{c}\text { Crisis - } \\
\text { Pre-Crisis }\end{array}$ \\
\hline \multirow[t]{2}{*}{ Financials } & mean & 2.94 & 1.71 & 5.86 & 4.15 \\
\hline & $\max$ & 15.87 & 3.76 & 15.87 & 12.11 \\
\hline \multirow[t]{2}{*}{ Consumer Disc. } & mean & 3.58 & 2.92 & 5.12 & 2.20 \\
\hline & $\max$ & 12.40 & 6.35 & 12.40 & 6.05 \\
\hline \multirow[t]{2}{*}{ Materials } & mean & 3.04 & 2.28 & 4.84 & 2.57 \\
\hline & $\max$ & 10.34 & 4.54 & 10.34 & 5.80 \\
\hline \multirow[t]{2}{*}{ Technology } & mean & 3.30 & 2.89 & 4.27 & 1.38 \\
\hline & $\max$ & 9.54 & 6.27 & 9.54 & 3.27 \\
\hline \multirow[t]{2}{*}{ Healthcare } & mean & 2.52 & 2.02 & 3.69 & 1.67 \\
\hline & $\max$ & 8.59 & 5.33 & 8.59 & 3.26 \\
\hline \multirow[t]{2}{*}{ Industrials } & mean & 2.90 & 2.62 & 3.57 & 0.95 \\
\hline & $\max$ & 7.04 & 5.17 & 7.04 & 1.87 \\
\hline \multirow[t]{2}{*}{ Consumer Staples } & mean & 2.28 & 1.96 & 3.05 & 1.09 \\
\hline & $\max$ & 7.90 & 3.82 & 7.90 & 4.08 \\
\hline \multirow[t]{2}{*}{ Utilities } & mean & 1.87 & 1.55 & 2.63 & 1.08 \\
\hline & $\max$ & 6.79 & 3.90 & 6.79 & 2.89 \\
\hline \multirow[t]{2}{*}{ Energy } & mean & 1.99 & 1.79 & 2.46 & 0.67 \\
\hline & $\max$ & 5.74 & 5.35 & 5.74 & 0.39 \\
\hline
\end{tabular}

This table reports the average basket-index put spread in the cost of insurance per dollar insured for the nine S\&P 500 sector ETFs. Numbers reported are in cents per dollar of the strike price. The full sample covers 1/2003-6/2009. The pre-crisis sample covers $1 / 2003-7 / 2007$. The crisis sample covers $8 / 2007-6 / 2009 . \Delta$ is 20 , time to maturity is 365 days. Sectors are listed in descending order by mean crisis spread. The last column reports the increase in sector put spread from pre-crisis to crisis in cents per dollar and percentage increase over pre-crisis spread, respectively. Spreads are constructed using strike-matching as described in Section 3. 
Table IV: Basket-Index Put Spreads (Actual vs. Black-Scholes Model)

\begin{tabular}{|c|c|c|c|c|c|c|c|c|c|c|c|c|c|c|c|c|}
\hline & & \multicolumn{7}{|c|}{ Financials } & \multicolumn{7}{|c|}{ Non-financials } & \multirow{3}{*}{$\begin{array}{r}\text { Difference } \\
\text { Spread } \\
\text { data-BS } \\
\end{array}$} \\
\hline & & \multicolumn{2}{|c|}{ Index } & \multicolumn{2}{|c|}{ Basket } & \multicolumn{3}{|c|}{ Basket-Index Spread } & \multicolumn{2}{|c|}{ Index } & \multicolumn{2}{|c|}{ Basket } & \multicolumn{3}{|c|}{ Basket-Index Spread } & \\
\hline & & (1) BS & (2) data & (3) $\mathrm{BS}$ & (4) data & (5) BS & (6) data & (7) data-BS & (1) BS & (2) data & (3) BS & (4) data & (5) BS & (6) data & (7) data-BS & \\
\hline Full & $\begin{array}{l}\text { mean } \\
\max \end{array}$ & $\begin{array}{r}5.04 \\
25.00\end{array}$ & $\begin{array}{r}5.15 \\
26.45\end{array}$ & $\begin{array}{r}8.70 \\
32.98\end{array}$ & $\begin{array}{r}8.08 \\
33.77\end{array}$ & $\begin{array}{l}3.66 \\
8.11\end{array}$ & $\begin{array}{r}2.94 \\
15.87\end{array}$ & $\begin{array}{r}-0.73 \\
9.30\end{array}$ & $\begin{array}{r}3.88 \\
11.62\end{array}$ & $\begin{array}{r}3.87 \\
12.15\end{array}$ & $\begin{array}{r}8.13 \\
15.21\end{array}$ & $\begin{array}{r}6.56 \\
19.25\end{array}$ & $\begin{array}{l}4.25 \\
6.97\end{array}$ & $\begin{array}{l}2.69 \\
7.58\end{array}$ & $\begin{array}{r}-1.57 \\
4.36\end{array}$ & $\begin{array}{l}0.84 \\
7.84\end{array}$ \\
\hline $\begin{array}{l}\text { Pre- } \\
\text { Crisis }\end{array}$ & $\begin{array}{l}\text { mean } \\
\text { max }\end{array}$ & $\begin{array}{l}3.13 \\
6.78\end{array}$ & $\begin{array}{l}3.15 \\
6.65\end{array}$ & $\begin{array}{r}6.60 \\
10.58\end{array}$ & $\begin{array}{l}4.86 \\
9.22\end{array}$ & $\begin{array}{l}3.47 \\
7.34\end{array}$ & $\begin{array}{l}1.71 \\
3.76\end{array}$ & $\begin{array}{r}-1.76 \\
1.37\end{array}$ & $\begin{array}{l}3.10 \\
5.45\end{array}$ & $\begin{array}{l}3.06 \\
5.10\end{array}$ & $\begin{array}{r}7.40 \\
10.49\end{array}$ & $\begin{array}{l}5.32 \\
9.65\end{array}$ & $\begin{array}{l}4.31 \\
6.97\end{array}$ & $\begin{array}{l}2.26 \\
4.57\end{array}$ & $\begin{array}{r}-2.05 \\
0.81\end{array}$ & $\begin{array}{l}0.29 \\
3.40\end{array}$ \\
\hline Crisis & $\begin{array}{l}\text { mean } \\
\text { max }\end{array}$ & $\begin{array}{r}9.61 \\
25.00\end{array}$ & $\begin{array}{r}9.91 \\
26.45\end{array}$ & $\begin{array}{l}13.72 \\
32.98\end{array}$ & $\begin{array}{l}15.77 \\
33.77\end{array}$ & $\begin{array}{l}4.11 \\
8.11\end{array}$ & $\begin{array}{r}5.86 \\
15.87\end{array}$ & $\begin{array}{l}1.75 \\
9.30\end{array}$ & $\begin{array}{r}5.76 \\
11.62\end{array}$ & $\begin{array}{r}5.81 \\
12.15\end{array}$ & $\begin{array}{r}9.87 \\
15.21\end{array}$ & $\begin{array}{r}9.51 \\
19.25\end{array}$ & $\begin{array}{l}4.11 \\
5.50\end{array}$ & $\begin{array}{l}3.70 \\
7.58\end{array}$ & $\begin{array}{r}-0.41 \\
4.36\end{array}$ & $\begin{array}{l}2.16 \\
7.84\end{array}$ \\
\hline
\end{tabular}

This table reports summary statistics for basket and index put prices for financials, non-financials and their difference (financials minus non-financials) comparing the Black-Scholes model predictions to the observed data. Numbers reported are in cents per dollar of strike price. The full sample covers $1 / 2003-6 / 2009$. The pre-crisis sample covers $1 / 2003-7 / 2007$. The crisis sample covers $8 / 2007-6 / 2009$. $\Delta$ is 20 . We choose the index option with the same weighted average strike as the individual options. We use implied volatilities for the index and the realized correlations to back out the implied volatility for the individual stocks. Daily pairwise conditional correlations for stocks are estimated using the exponential smoother with smoothing parameter 0.95 . Pairwise correlations within the sector are then averaged each day, weighted by the pairs' combined market equity. 
Table V: Correlations implied by Black-Scholes

\begin{tabular}{|c|c|c|c|c|c|c|c|c|c|c|c|}
\hline & & \multicolumn{5}{|c|}{ Financials } & \multicolumn{5}{|c|}{ Non-financials } \\
\hline & & & \multicolumn{2}{|c|}{ Puts } & \multicolumn{2}{|c|}{ Calls } & & \multicolumn{2}{|c|}{ Puts } & \multicolumn{2}{|c|}{ Calls } \\
\hline \multirow{3}{*}{ Full } & & Actual & Implied & Spread & Implied & Spread & Actual & Implied & Spread & Implied & Spread \\
\hline & mean & 0.51 & 0.62 & 0.11 & 0.66 & 0.15 & 0.39 & 0.55 & 0.15 & 0.43 & 0.04 \\
\hline & $\max$ & 0.74 & 0.85 & 0.41 & 0.87 & 0.37 & 0.75 & 0.73 & 0.43 & 0.56 & 0.19 \\
\hline \multirow[t]{2}{*}{ Pre-Crisis } & mean & 0.45 & 0.64 & 0.19 & 0.62 & 0.17 & 0.34 & 0.54 & 0.20 & 0.42 & 0.08 \\
\hline & $\max$ & 0.73 & 0.80 & 0.41 & 0.76 & 0.37 & 0.57 & 0.71 & 0.43 & 0.52 & 0.19 \\
\hline \multirow{2}{*}{ Crisis } & mean & 0.65 & 0.57 & -0.07 & 0.74 & 0.09 & 0.52 & 0.56 & 0.04 & 0.47 & -0.04 \\
\hline & $\max$ & 0.74 & 0.85 & 0.23 & 0.87 & 0.25 & 0.75 & 0.73 & 0.30 & 0.56 & 0.14 \\
\hline
\end{tabular}

This table compares realized correlations to Black-Scholes implied correlations from put and call options. The implied correlation is chosen such that the basket-index spread in the data equals the Black-Scholes basket-index spread. The full sample covers $1 / 2003-6 / 2009$. The pre-crisis sample covers $1 / 2003-7 / 2007$. The crisis sample covers $8 / 2007-6 / 2009 . \Delta$ is 20 . We choose the index option with the same strike as the individual options. We use implied volatilities for the index. Daily pairwise conditional correlations for stocks are estimated using the exponential smoother with smoothing parameter 0.95. Pairwise correlations within the sector are then averaged each day, weighted by the pairs' combined market equity. 
Table VI: Basket-Index Put Spreads for Largest Banks (Actual vs. Model with Bailout)

\begin{tabular}{ll|cc|cccccccccccc}
\hline & & Basket & Big 12 & $C$ & AIG & BoA & JP & Wells & Wach & GS & Amex & MS & Merrill & Fannie & Freddie \\
\hline \multirow{2}{*}{ Pre-Crisis } & mean & 0.20 & -0.16 & -0.02 & 0.77 & -0.95 & -0.58 & 1.08 & 0.24 & -0.34 & -0.07 & -1.08 & -0.38 & -0.57 & 0.02 \\
& max & 3.70 & 2.89 & 2.26 & 3.04 & 4.21 & 3.32 & 3.16 & 3.21 & 1.69 & 2.42 & 2.37 & 2.27 & 3.11 & 3.61 \\
Crisis & mean & 1.69 & -1.11 & -0.92 & -0.59 & -3.70 & -0.49 & -0.10 & -5.35 & -0.48 & 1.79 & -4.60 & -1.05 & 0.63 & 1.51 \\
& max & 13.58 & 19.49 & 27.71 & 18.38 & 41.78 & 14.00 & 15.39 & 13.49 & 17.48 & 18.84 & 25.77 & 9.12 & 12.88 & 19.10 \\
\hline
\end{tabular}

This table reports the difference between the actual and the BS price put option price (per dollar insured). Numbers reported are in cents per dollar of strike price. The full sample covers $1 / 2003-6 / 2009$. The pre-crisis sample covers $1 / 2003-7 / 2007$. The crisis sample covers $8 / 2007-6 / 2009$. $\Delta$ is 20 . We choose the index option with the same weighted average strike as the individual options. We use a one-year-ahead GARCH-based forecast for stock return volatilities. Rolling volatilities are estimated from daily returns using a one year backward looking window. The cost of the basket is computed as described in Section 4.1. Data for Wachovia and Merrill Lynch end in December 2008, while data for Freddie Mac and Fannie Mae end in September 2008. For these four firms that exit the sample early, the reported averages for the crisis period end at their exit date. 
Table VII: Basket-Index Spreads (Actual and Bailout Model vs. Model without Bailout)

\begin{tabular}{|c|c|c|c|c|c|c|c|c|c|c|c|}
\hline & & \multirow{2}{*}{$\begin{array}{r}\text { Data Minus } \\
\text { No Bailout }\end{array}$} & \multicolumn{9}{|c|}{ Models: Bailout Minus No Bailout } \\
\hline & & & $\underline{J}=0.20$ & 0.30 & 0.40 & 0.50 & 0.60 & 0.70 & 0.80 & 0.90 & $\infty$ \\
\hline & & & \multicolumn{9}{|c|}{ Panel I: Financials } \\
\hline Full & $\begin{array}{l}\text { mean } \\
\max \end{array}$ & $\begin{array}{r}-0.73 \\
9.30\end{array}$ & $\begin{array}{l}0.71 \\
2.81\end{array}$ & $\begin{array}{l}0.62 \\
4.63\end{array}$ & $\begin{array}{l}0.54 \\
6.55\end{array}$ & $\begin{array}{l}0.52 \\
7.98\end{array}$ & $\begin{array}{l}0.44 \\
8.13\end{array}$ & $\begin{array}{l}0.29 \\
9.10\end{array}$ & $\begin{array}{r}0.17 \\
10.95\end{array}$ & $\begin{array}{l}0.08 \\
7.60\end{array}$ & $\begin{array}{l}0.00 \\
0.00\end{array}$ \\
\hline Pre-Crisis & $\begin{array}{l}\text { mean } \\
\max \end{array}$ & $\begin{array}{r}-1.76 \\
1.37\end{array}$ & $\begin{array}{l}0.71 \\
2.08\end{array}$ & $\begin{array}{l}0.15 \\
2.40\end{array}$ & $\begin{array}{r}-0.00 \\
0.79\end{array}$ & $\begin{array}{r}-0.02 \\
0.15\end{array}$ & $\begin{array}{l}-0.01 \\
-0.00\end{array}$ & $\begin{array}{l}-0.01 \\
-0.00\end{array}$ & $\begin{array}{l}-0.00 \\
-0.00\end{array}$ & $\begin{array}{l}-0.00 \\
-0.00\end{array}$ & $\begin{array}{l}0.00 \\
0.00\end{array}$ \\
\hline Crisis & $\begin{array}{l}\text { mean } \\
\max \end{array}$ & $\begin{array}{l}1.75 \\
9.30\end{array}$ & $\begin{array}{l}0.71 \\
2.81\end{array}$ & $\begin{array}{l}1.75 \\
4.63\end{array}$ & $\begin{array}{l}1.84 \\
6.55\end{array}$ & $\begin{array}{l}1.79 \\
7.98\end{array}$ & $\begin{array}{l}1.52 \\
8.13\end{array}$ & $\begin{array}{l}1.00 \\
9.10\end{array}$ & $\begin{array}{r}0.58 \\
10.95\end{array}$ & $\begin{array}{l}0.29 \\
7.60\end{array}$ & $\begin{array}{l}0.00 \\
0.00\end{array}$ \\
\hline & & & \multicolumn{9}{|c|}{ Panel II: Non-financials } \\
\hline Full & $\begin{array}{l}\text { mean } \\
\max \end{array}$ & $\begin{array}{r}-1.09 \\
4.46\end{array}$ & $\begin{array}{l}0.63 \\
1.60\end{array}$ & $\begin{array}{l}0.64 \\
3.16\end{array}$ & $\begin{array}{l}0.28 \\
3.70\end{array}$ & $\begin{array}{l}0.10 \\
3.23\end{array}$ & $\begin{array}{l}0.02 \\
3.27\end{array}$ & $\begin{array}{r}-0.00 \\
2.06\end{array}$ & $\begin{array}{r}-0.01 \\
0.90\end{array}$ & $\begin{array}{r}-0.01 \\
0.32\end{array}$ & $\begin{array}{l}0.00 \\
0.00\end{array}$ \\
\hline Pre-Crisis & $\begin{array}{l}\text { mean } \\
\max \end{array}$ & $\begin{array}{r}-1.48 \\
0.97\end{array}$ & $\begin{array}{l}0.59 \\
1.00\end{array}$ & $\begin{array}{l}0.33 \\
1.83\end{array}$ & $\begin{array}{l}0.04 \\
0.83\end{array}$ & $\begin{array}{r}-0.01 \\
0.17\end{array}$ & $\begin{array}{l}-0.01 \\
-0.00\end{array}$ & $\begin{array}{l}-0.01 \\
-0.00\end{array}$ & $\begin{array}{l}-0.00 \\
-0.00\end{array}$ & $\begin{array}{l}-0.00 \\
-0.00\end{array}$ & $\begin{array}{l}0.00 \\
0.00\end{array}$ \\
\hline Crisis & $\begin{array}{l}\text { mean } \\
\max \end{array}$ & $\begin{array}{r}-0.17 \\
4.46\end{array}$ & $\begin{array}{l}0.73 \\
1.60\end{array}$ & $\begin{array}{l}1.38 \\
3.16\end{array}$ & $\begin{array}{l}0.85 \\
3.70\end{array}$ & $\begin{array}{l}0.38 \\
3.23\end{array}$ & $\begin{array}{l}0.11 \\
3.27\end{array}$ & $\begin{array}{l}0.01 \\
2.06\end{array}$ & $\begin{array}{r}-0.02 \\
0.90\end{array}$ & $\begin{array}{r}-0.02 \\
0.32\end{array}$ & $\begin{array}{l}0.00 \\
0.00\end{array}$ \\
\hline
\end{tabular}

This table reports summary statistics for the BS-adjusted basket-index put spread in the data and in the model with bailouts. Numbers reported are in percent of the strike price. The full sample covers $1 / 2003-6 / 2009$. The pre-crisis sample covers $1 / 2003-7 / 2007$. The crisis sample covers $8 / 2007-6 / 2009 . \Delta$ is 20 . We choose the index option with the same weighted average strike as the individual options. We use implied volatilities for the index and the realized correlations to back out the implied volatility for the individual stocks. Daily pairwise conditional correlations for stocks are estimated using the exponential smoother with smoothing parameter 0.95. Pairwise correlations within the sector are then averaged each day, weighted by the pairs' combined market equity. 
Table VIII: Liquidity in Puts

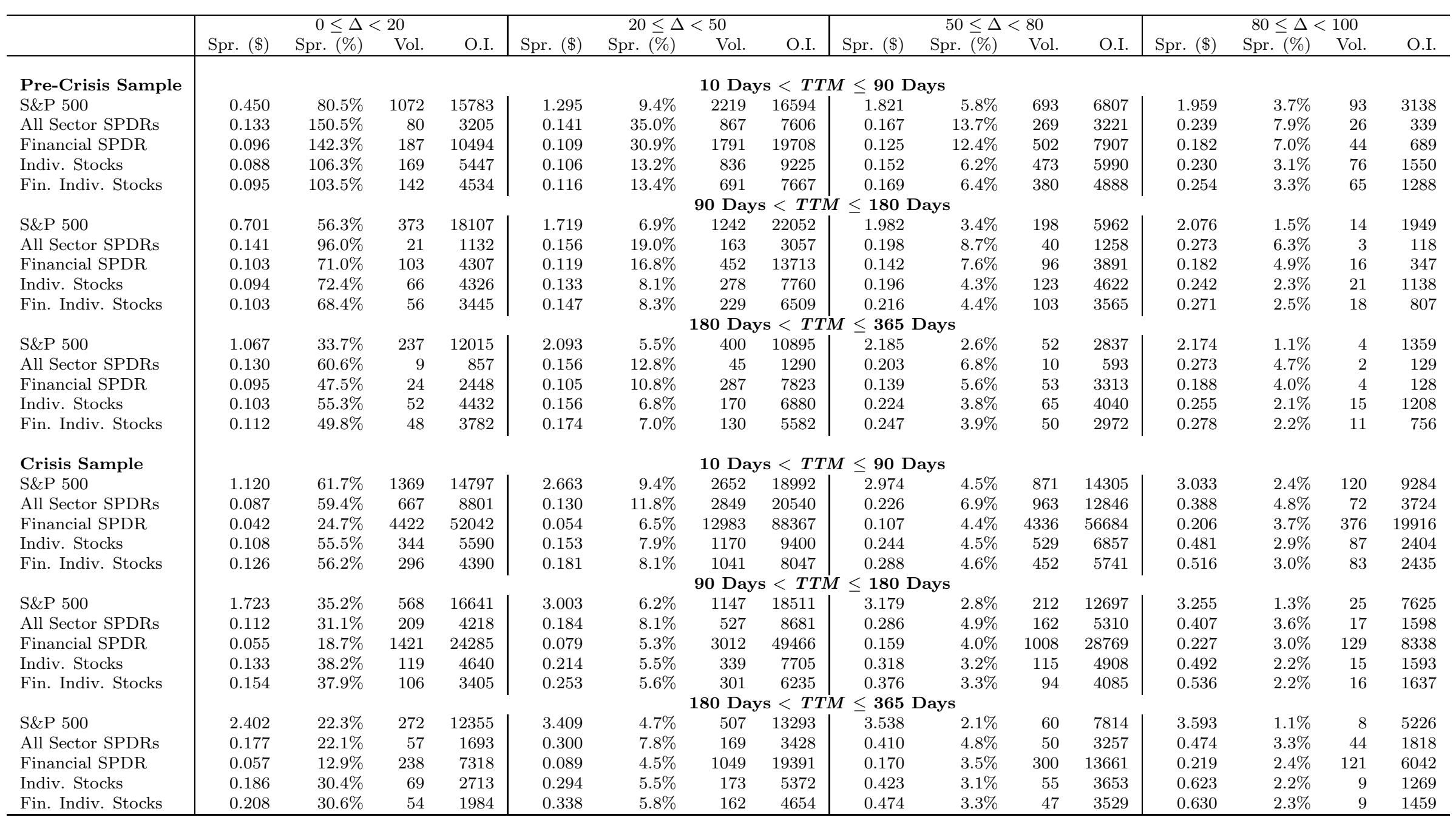

The full sample covers $1 / 2003-6 / 2009$. The pre-crisis sample covers $1 / 2003-7 / 2007$. The crisis sample covers $8 / 2007-6 / 2009$. The stats reported for individual and sector options are value-weighted. 
Table IX: Liquidity in Calls

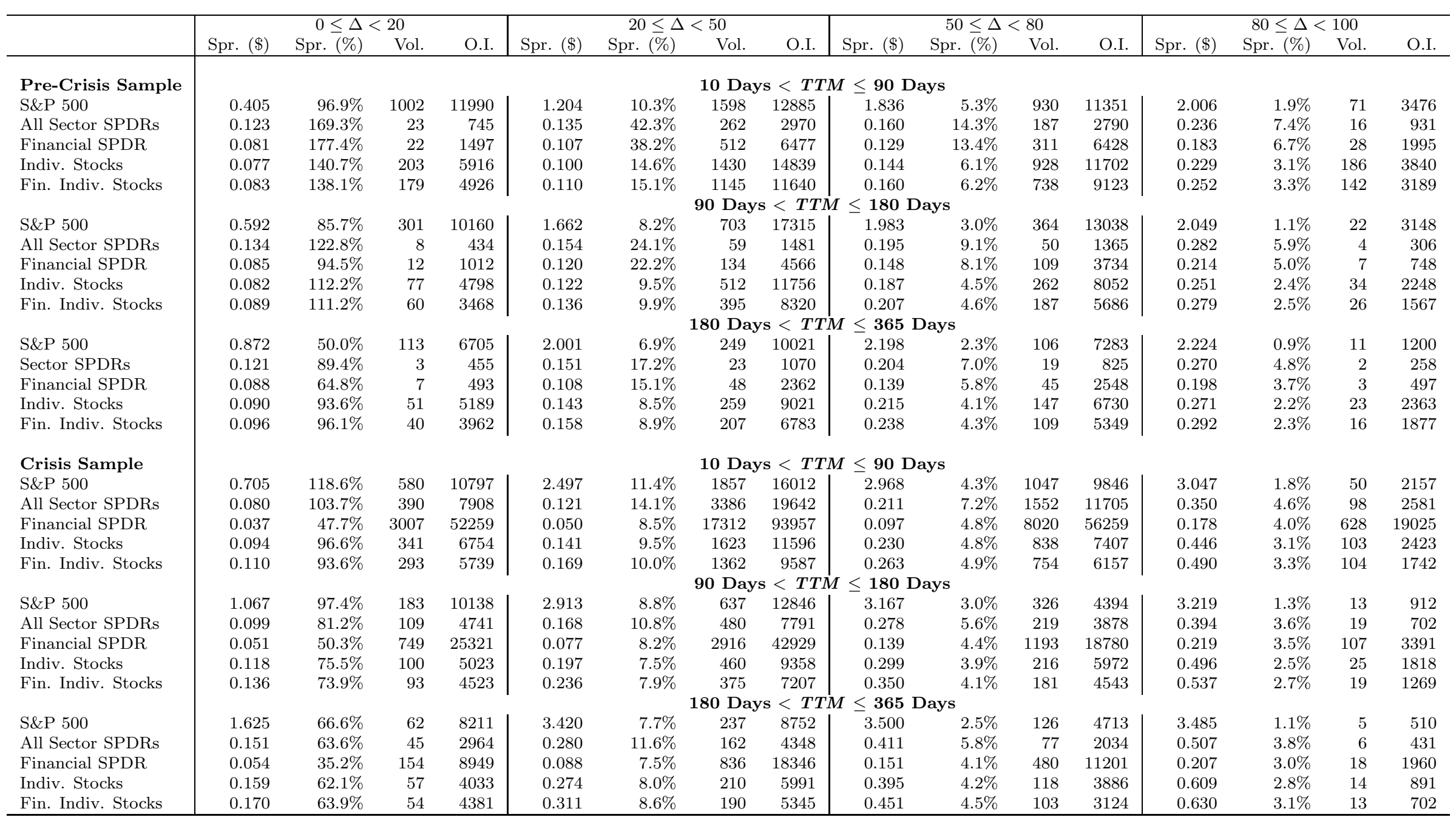

The full sample covers $1 / 2003-6 / 2009$. The pre-crisis sample covers $1 / 2003-7 / 2007$. The crisis sample covers $8 / 2007-6 / 2009$. The stats reported for individual and sector options are value-weighted. 
Financials--Puts

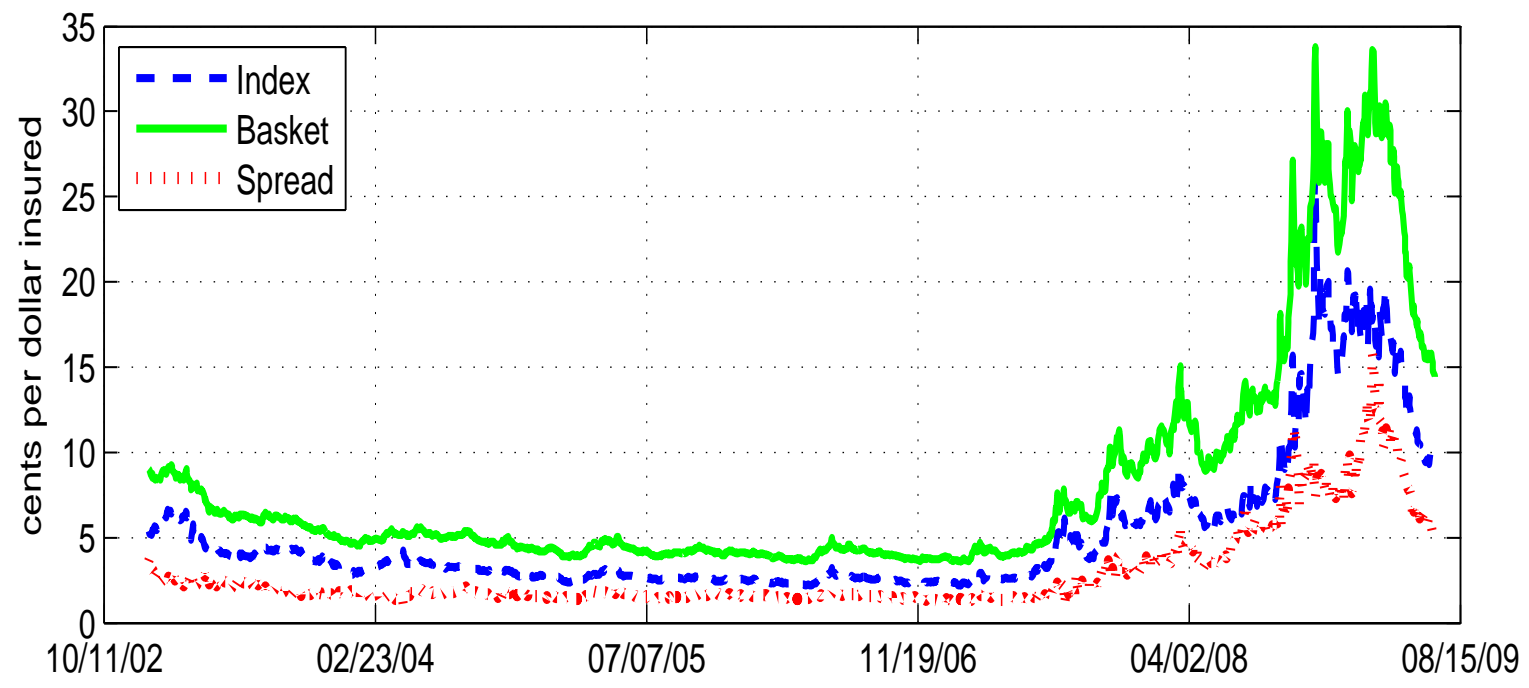

Financials--Calls

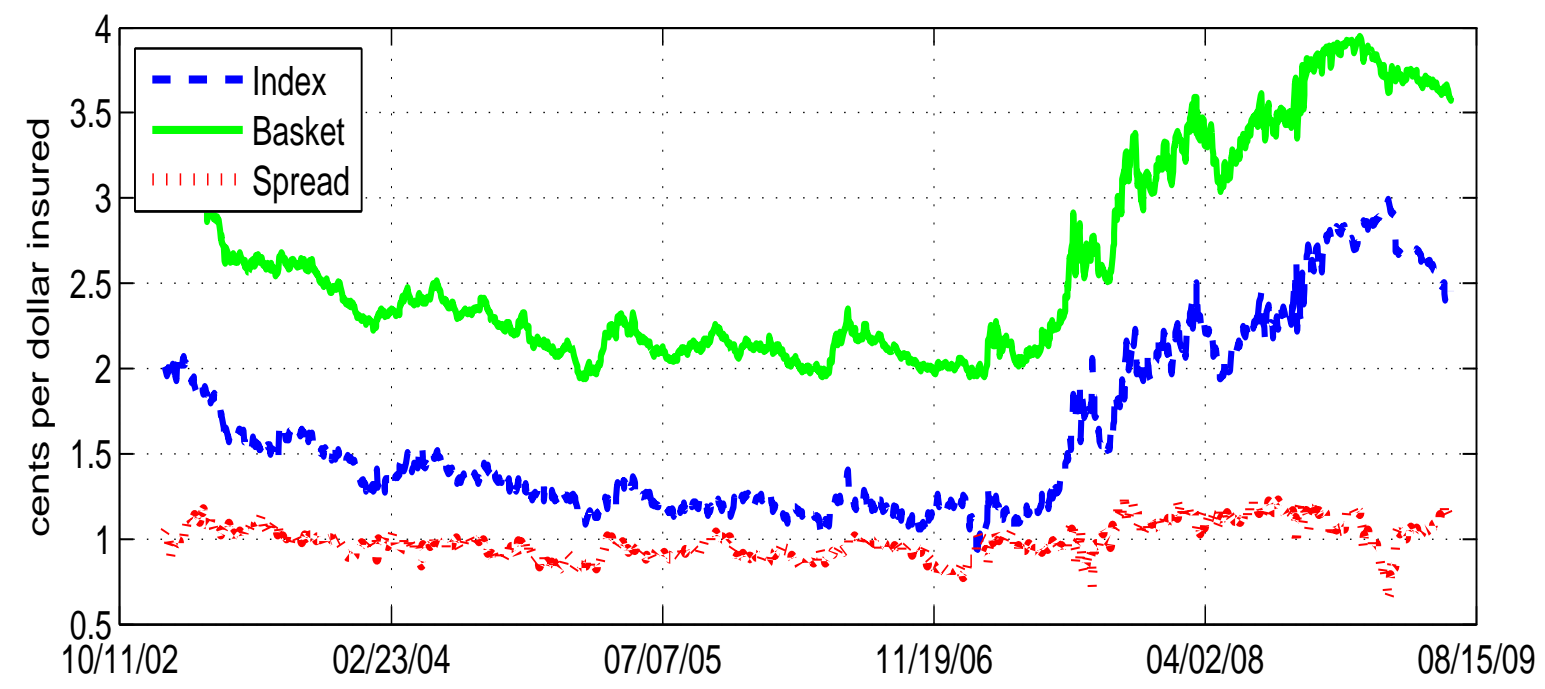

Figure 1: Cost Per Dollar Insured - Financial Sector

The dashed (full) line shows the cost per dollar insured for the index Call $_{\text {cdi } f \text { f }}^{\text {index }}$ (basket, Call $_{\text {cdi }, f}^{\text {basket }}$ ). The dotted line plots their difference. $\Delta$ is 20 for the index option. Time to maturity is 365 days. The top panel looks at puts. The bottom looks at calls. Spreads are constructed using strike-matching as described in Section 3. 


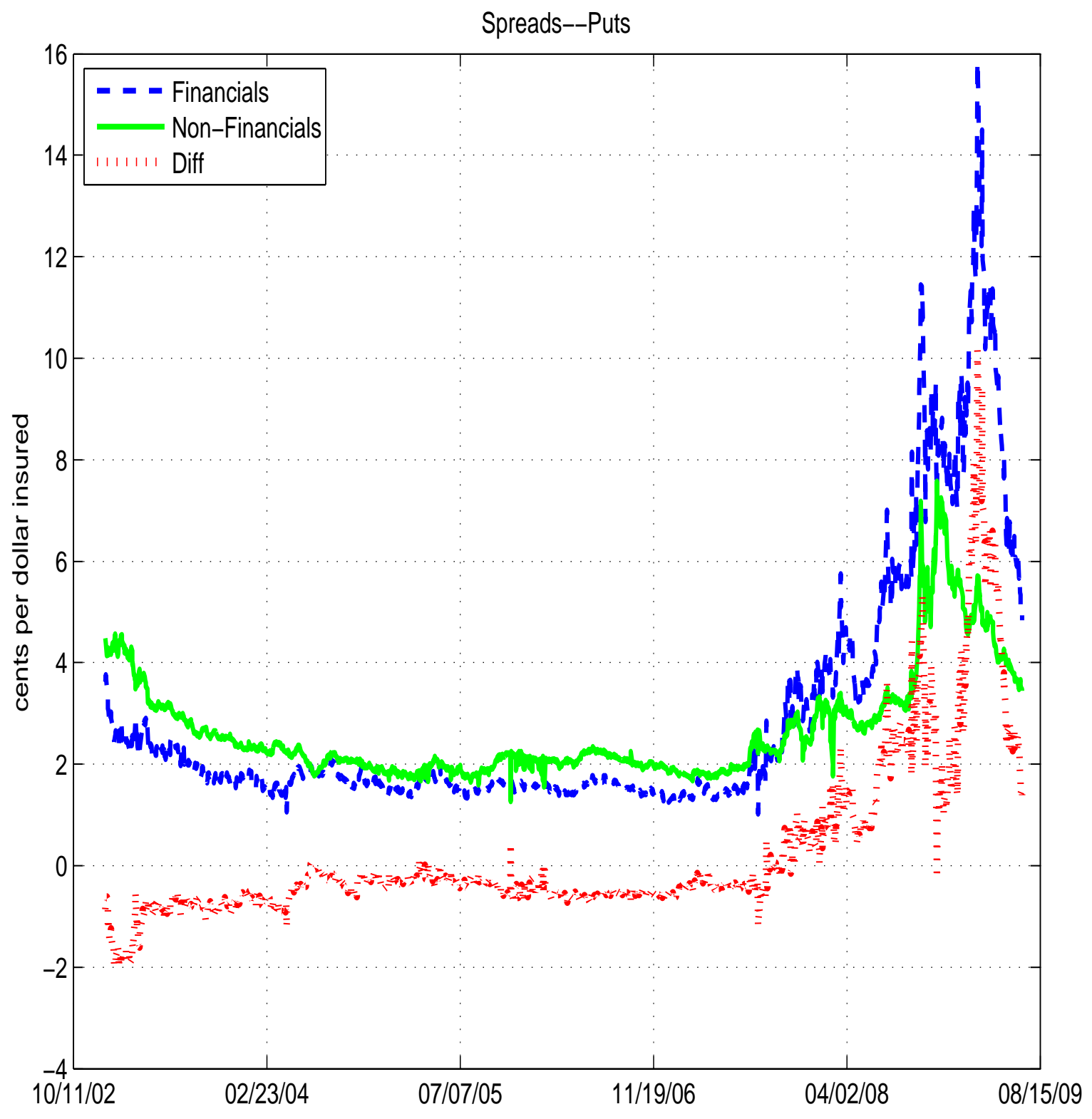

Figure 2: Basket-Index Spread in Cost Per Dollar Insured Inferred from Puts

The dashed (full) line shows the difference in the cost per dollar insured between the basket and the index: Put $t_{c d i, i}^{\text {basket }}-P u t_{\text {cdi,i }}^{\text {index }}$ for financials (non-financials). The dotted line plots their difference. $\Delta$ is 20 for the index option. Time to maturity is 365 days. We choose the individual options with the same strike as the index option. 
Put Implied Volatility: Basket Minus Index

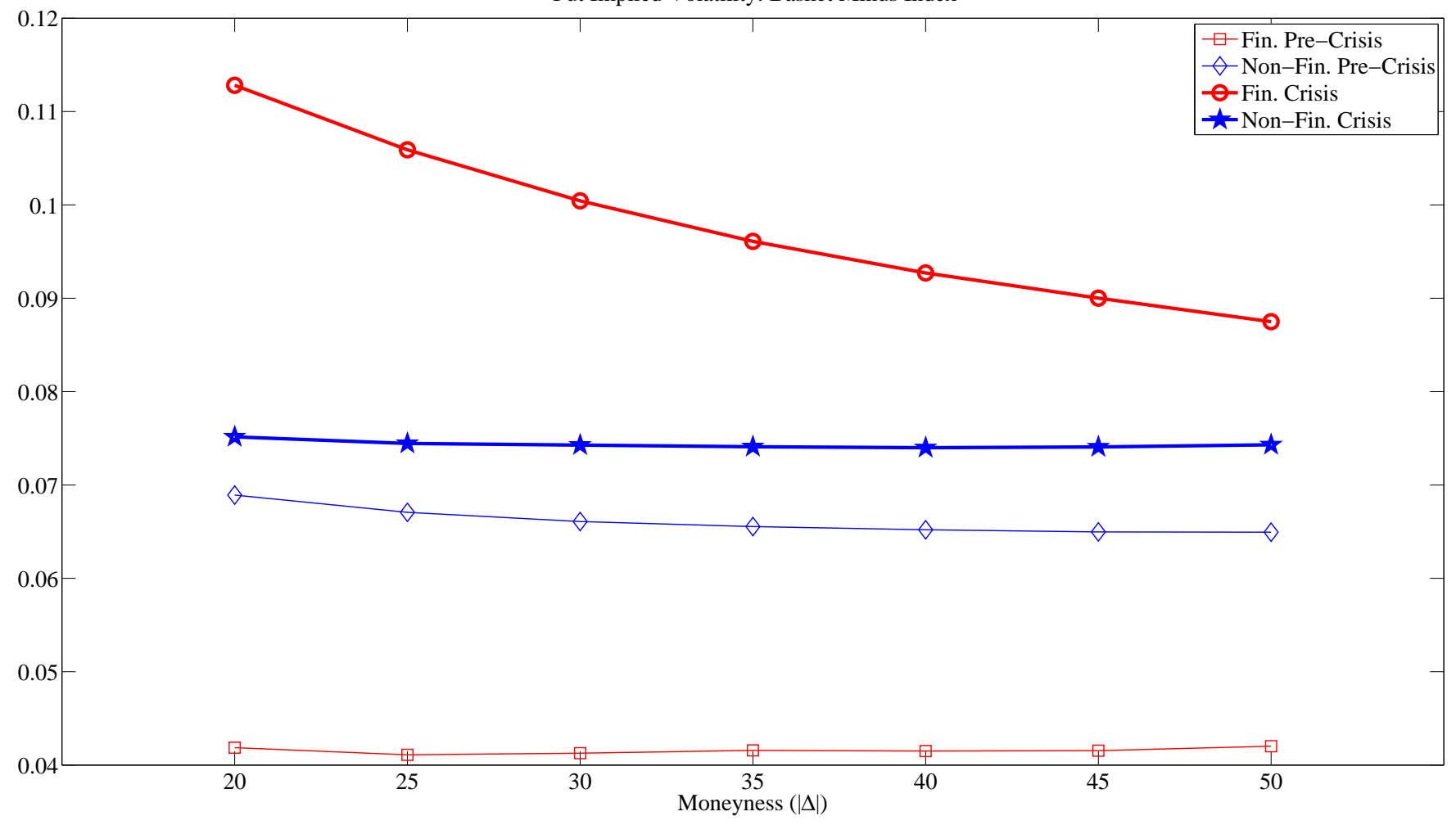

Call Implied Volatility: Basket Minus Index

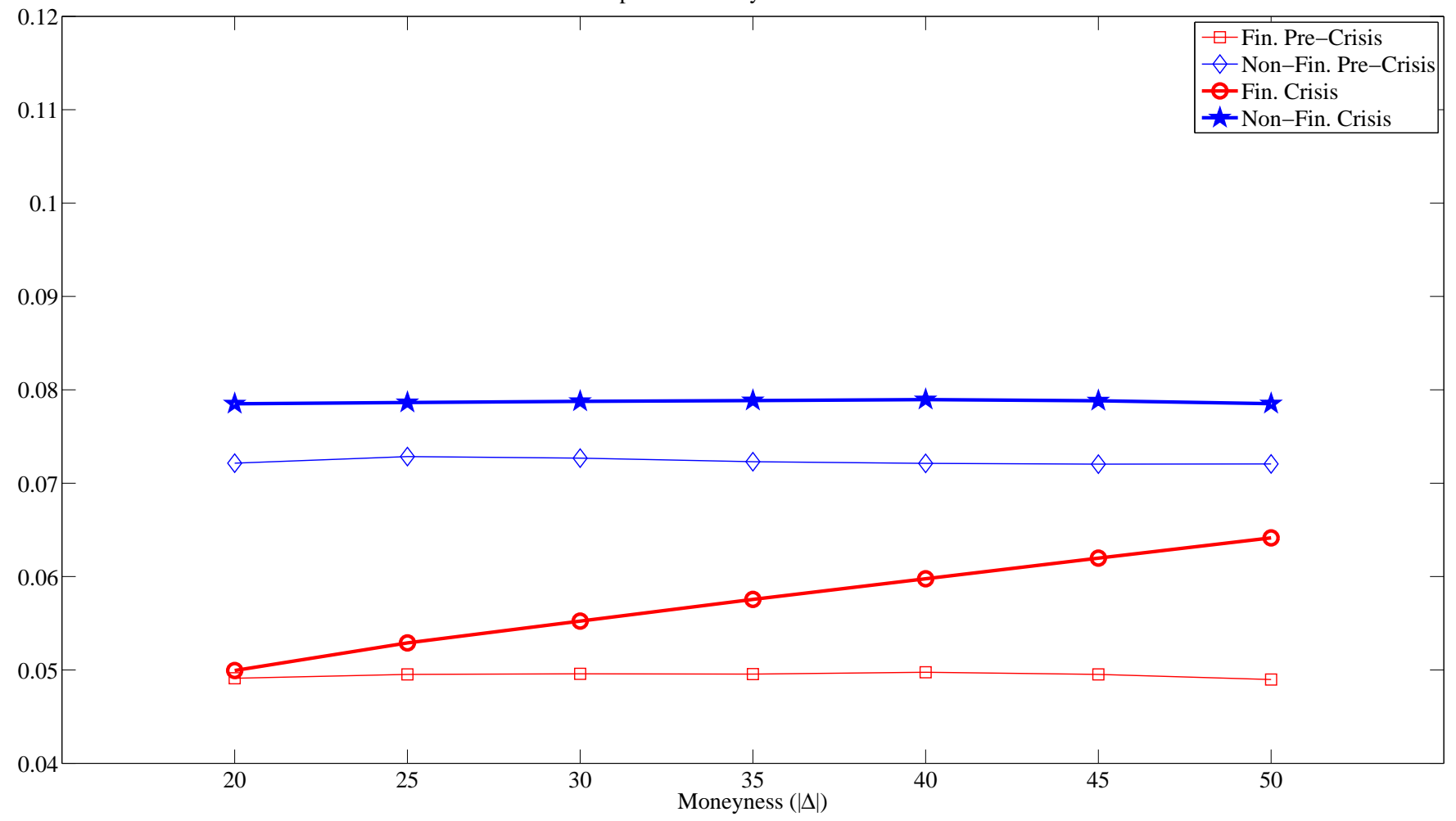

Figure 3: Implied Volatility Skew Inferred from Calls

The figure plots the average implied volatility difference (basket minus index) inferred from puts (top panel) and calls (bottom panel) for financials and non-financials against moneyness. The pre-crisis sanglple covers 1/2003-7/2007. The crisis sample covers 8/2007-6/2009. 

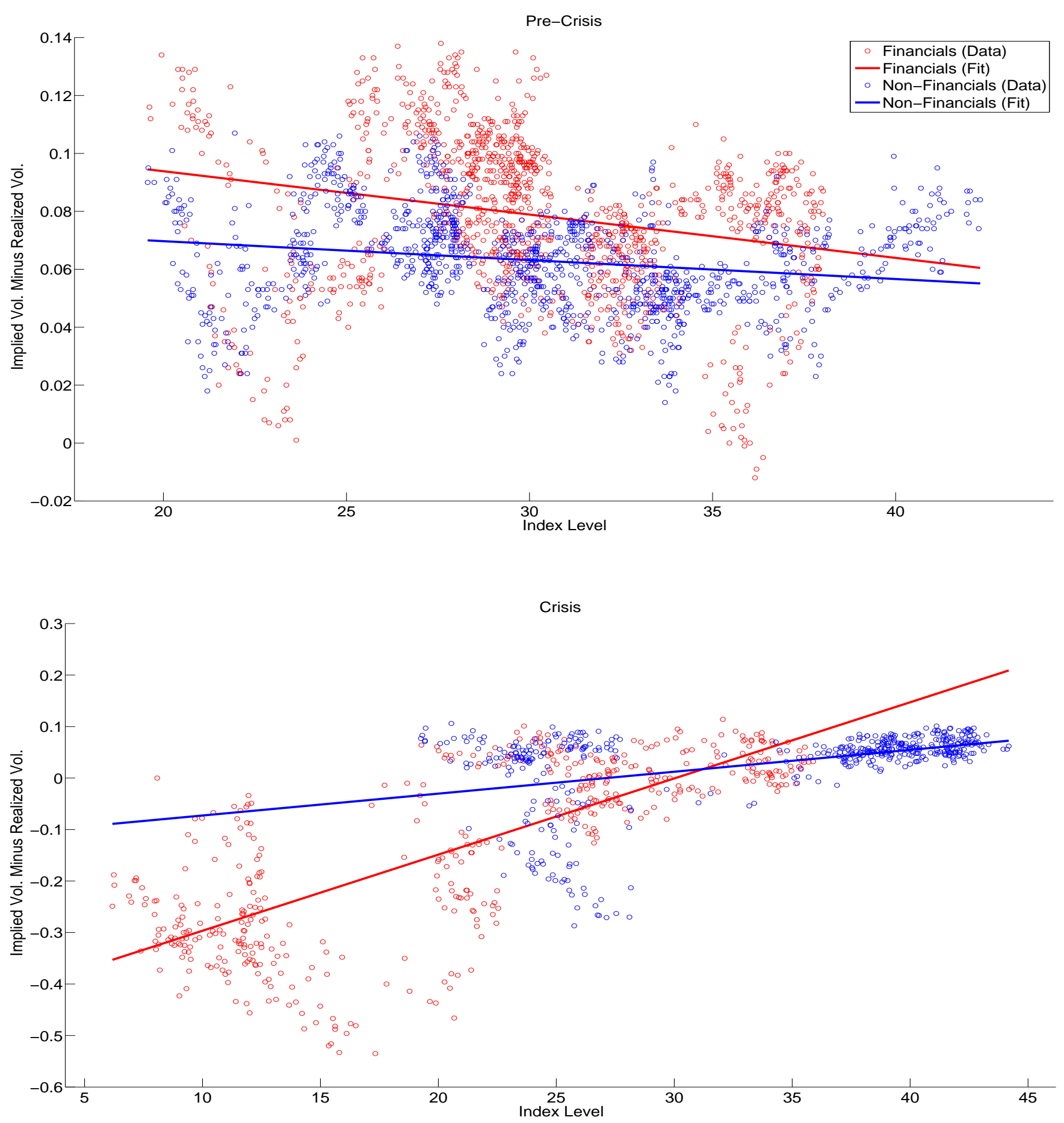

Figure 4: Implied Volatility Minus Realized Volatility Versus Index Level

The figure plots the difference between Black-Scholes implied volatility (using $|\Delta|=20$ and $T T M=365$ options) and realized volatility against the price level on the financial sector ETF and value-weighted average price of the eight non-financial sector ETFs, as well as the best fit line for each sector. The first figure shows data and fit for the pre-crisis sample $(1 / 2003-7 / 2007)$ and the second figure shows the crisis sample (8/2007-6/2009). In order to align realized volatility with the forward-looking nature of one year implied volatility, we calculate realized volatility using a forward-looking 252-day rolling volatility of daily returns on the underlying. Our estimated effects are quantitatively robust to using backward looking rolling windows and shorter window lengths. 


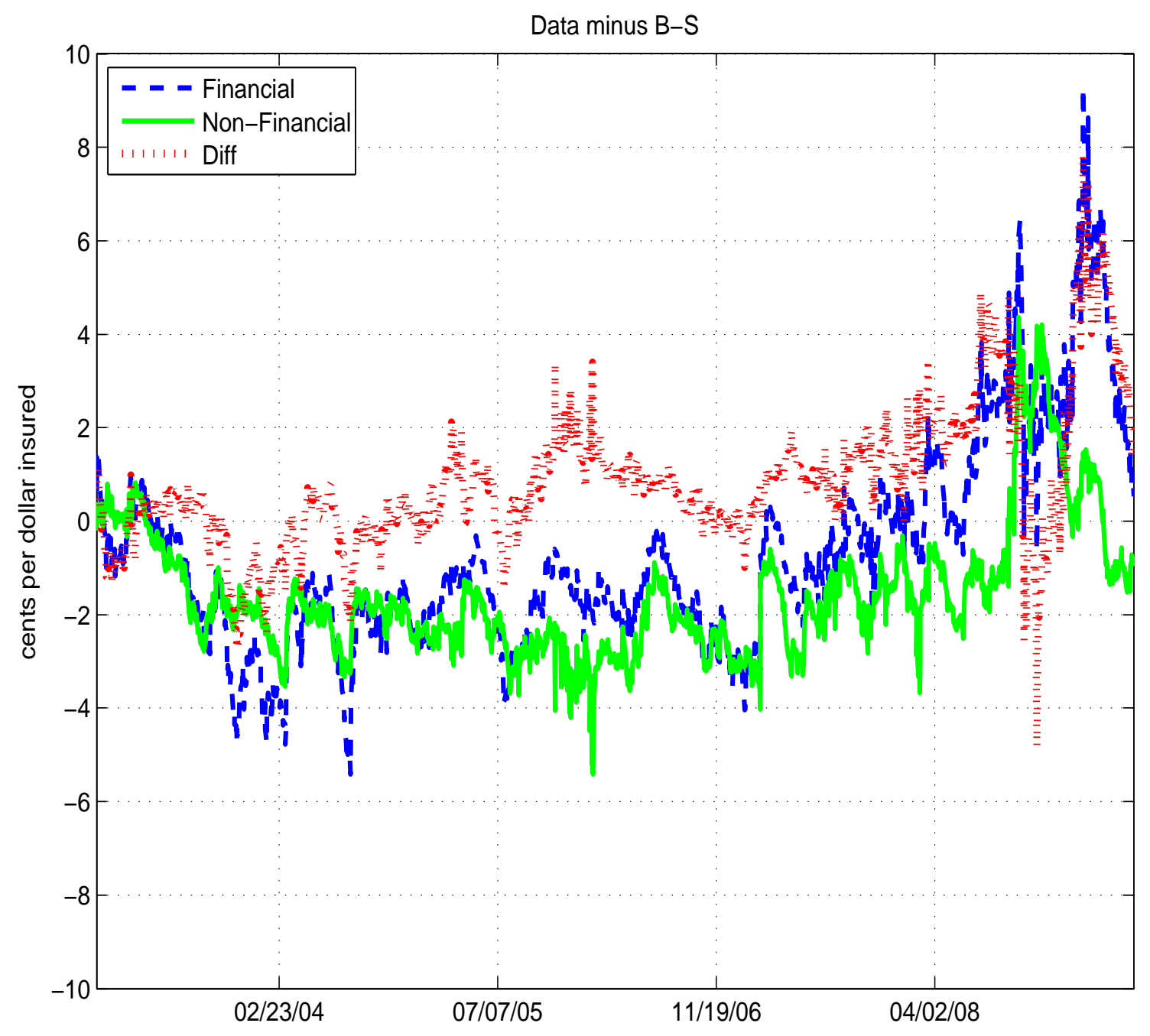

Figure 5: Basket-Index Put Spreads (Actual Minus Black-Scholes Model)

The dashed (full) line shows the actual minus Black-Scholes basket-index put spread for the financials (non-financials). The dotted line plots their difference. $\Delta$ is 20 . Time to maturity is 365 days. We choose the index option with the same strike as the individual options. 


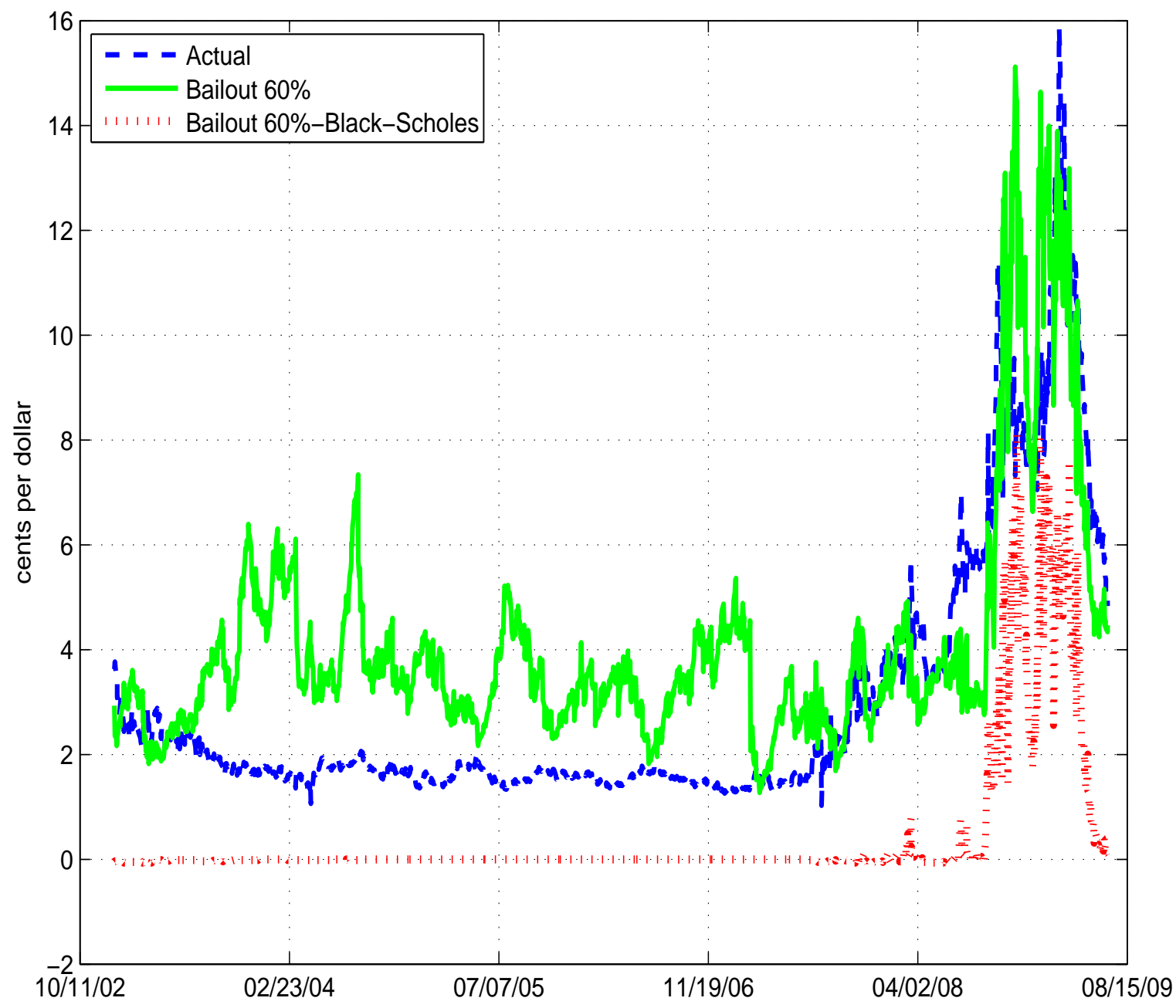

Figure 6: Basket-Index Put Spreads (Actual vs. Model with Bailout)

The dashed line shows the observed basket-index put spread for financials. The dashed line plots the same object for the single-factor model with bailouts. The dotted line plots the difference between the basket-index put spreads for the single-factor model with bailout minus that implied by the single-factor model without bailout guarantee. $\Delta$ is 20 and time to maturity is 365 days. We choose the index option with the same strike as the individual options. We use the implied volatility for the index and the realized correlations to back out the implied volatility for the individual stocks. Daily pairwise conditional correlations for stocks are estimated using the exponential smoother with smoothing parameter 0.95. Pairwise correlations within the sector are then averaged each day, weighted by the pairs' combined market equity. 
Panel I: Difference-in-differences (data minus Black-Scholes and basket minus index)
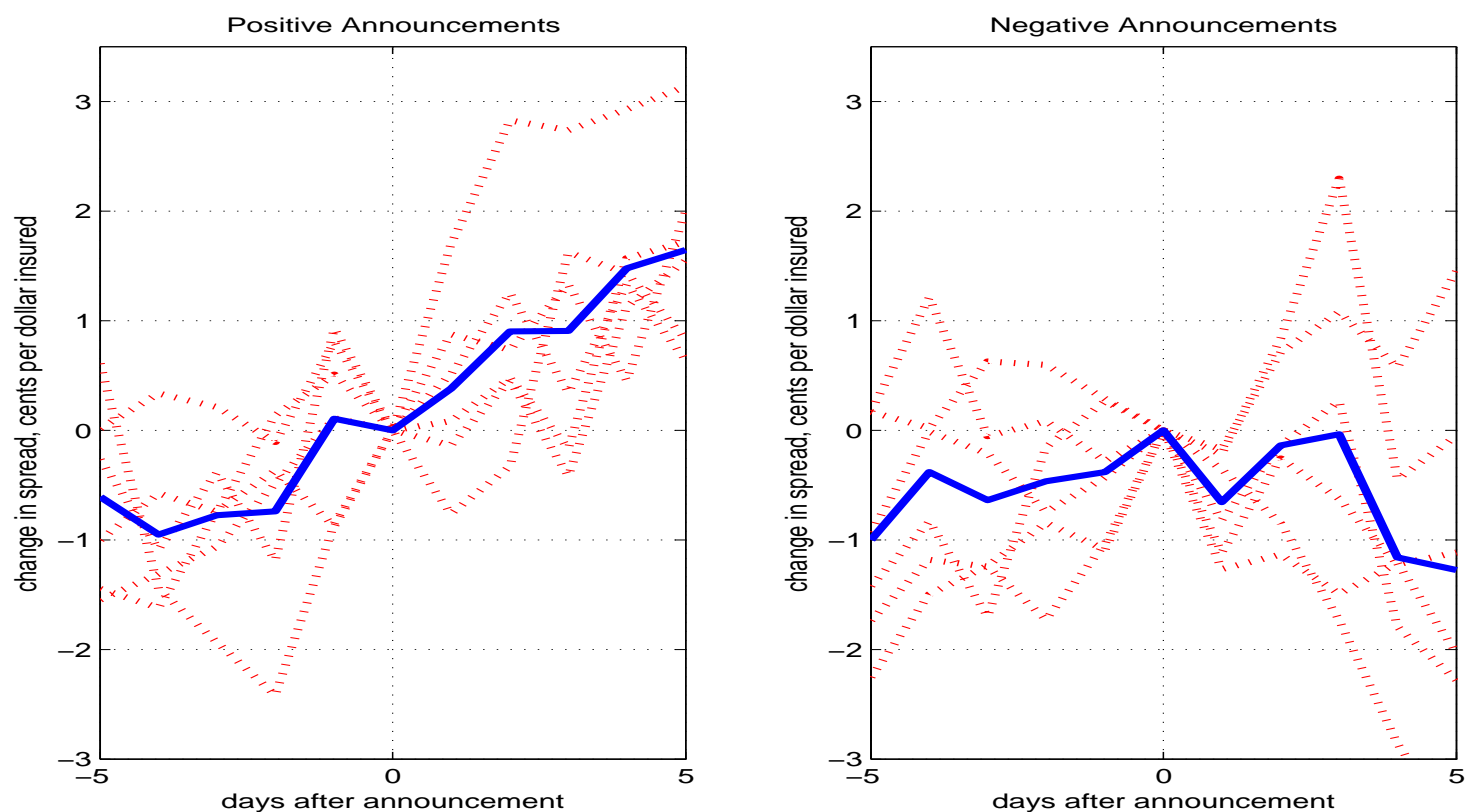

Panel II: Triple Difference (financials minus non-financials, data minus Black-Scholes, and basket minus index)
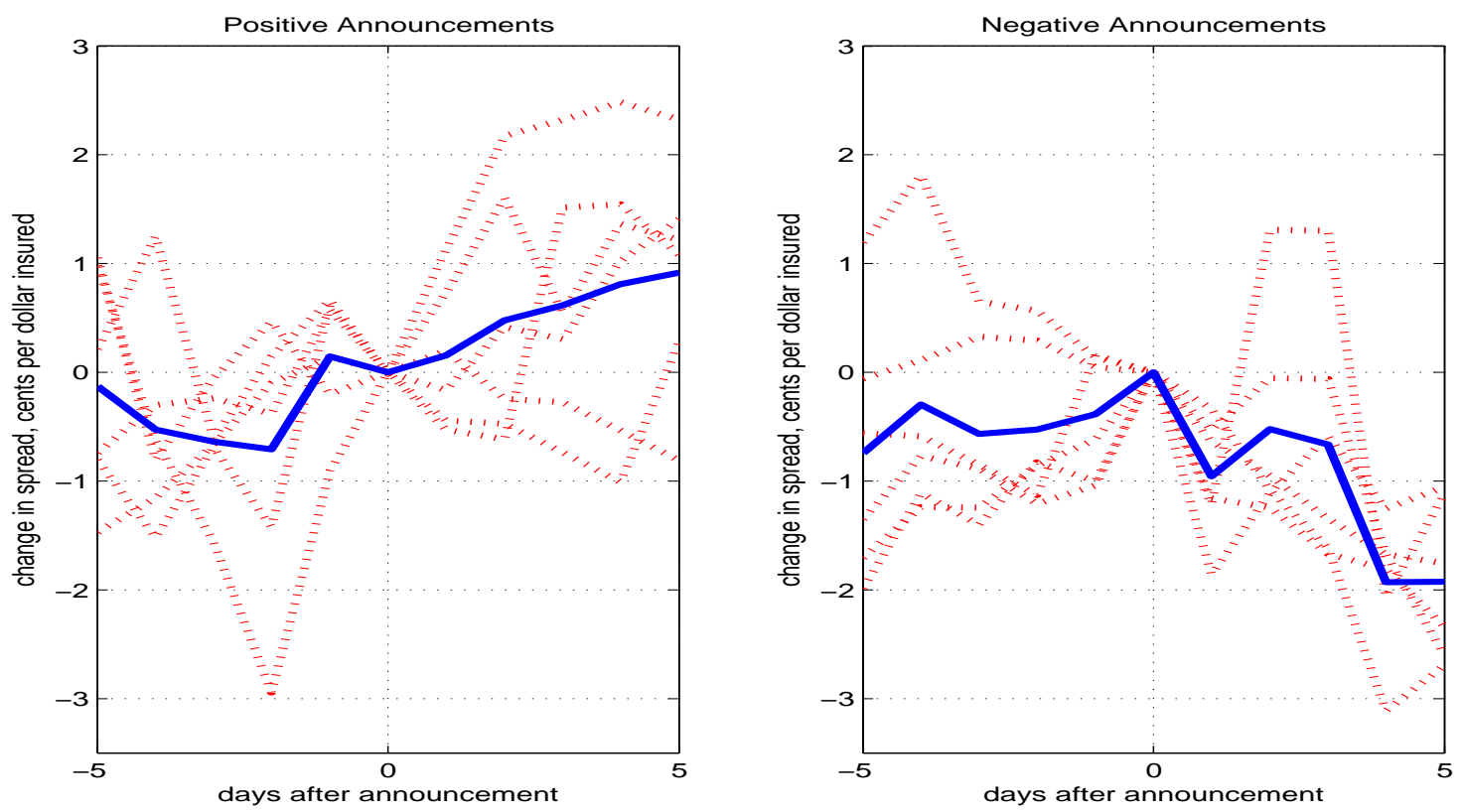

Figure 7: Basket-Index Spread Event Study Around Government Announcements

Panel I shows the basket-index spread difference-in-differences (data minus Black-Scholes and basket minus index) around announcement dates. Panel II shows the basket-index spread triple difference (financials minus non-financials, data minus Black-Scholes, and basketindex) around announcement dates. Figures on the left and right show responses to positive and negative announcements, respectively. In each figure, the solid line shows the average spread response over all announcements, and the dotted lines show the responses to each individual announcement. Spreads use options with $\Delta=20$ and $T T M=365$, and are constructed using strike-matching. BS basket-index spreads are computed using the implied index volatility. 


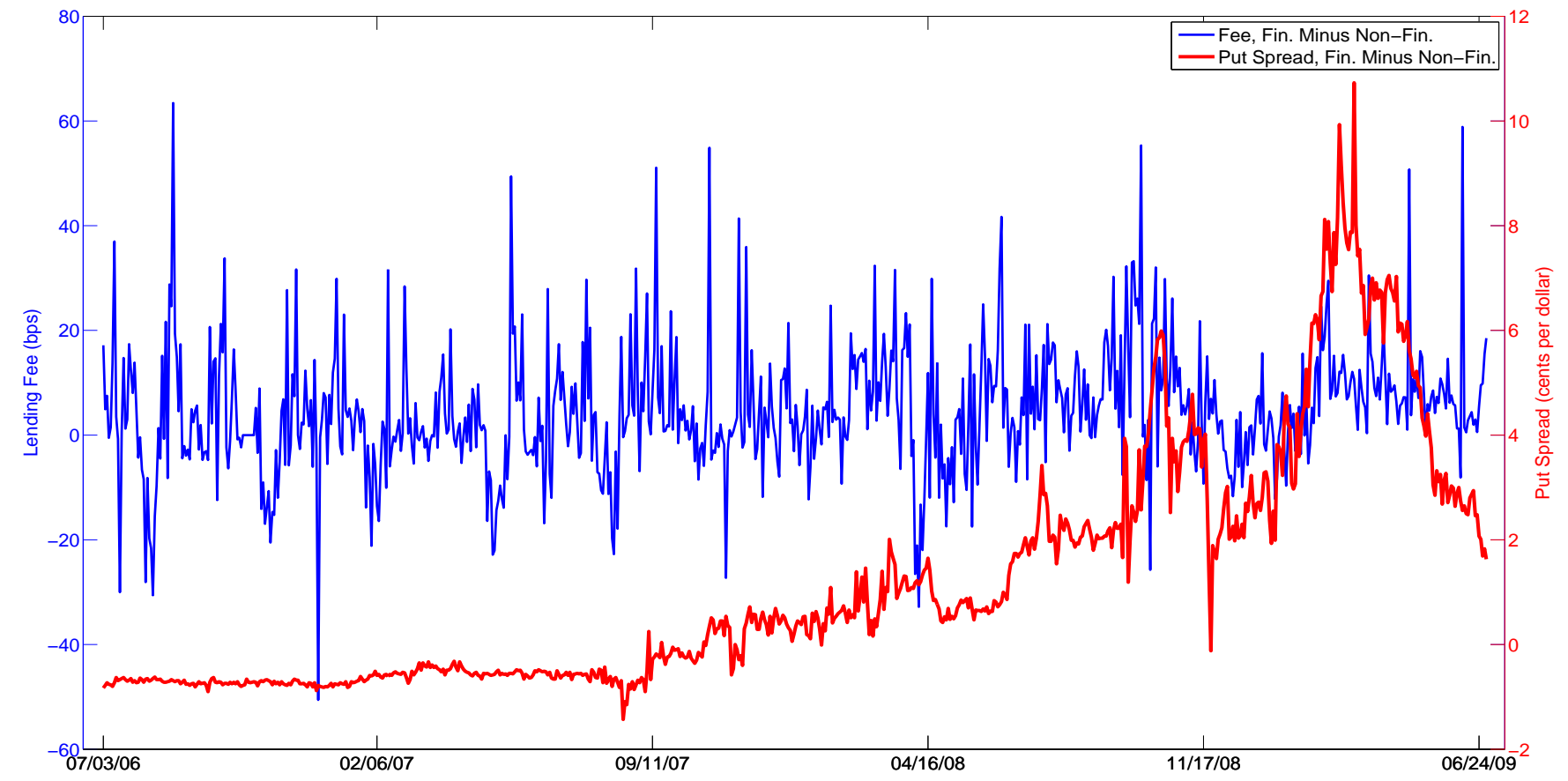

Figure 8: Short Sale Lending Fees Versus Put Spreads

The red line shows the difference in put spreads (financials minus non-financials, $\Delta=20$ and $T T M=365$ ) in cents per dollar insured (corresponding to the right vertical axis). The red line shows the difference in value-weighted securities lending fees (financials minus non-financials) in basis points (corresponding to the left vertical axis). 


\section{Separate Appendix-Not for Publication}

\section{A Data Appendix}

The S\&P 500 Index is an unmanaged index of 500 common stocks that is generally considered representative of the U.S. stock market. The Select Sector SPDR Trust consists of nine separate investment portfolios (each a 'Select Sector SPDR Fund' or a 'Fund' and collectively the 'Select Sector SPDR Funds' or the 'Funds'). Each Select Sector SPDR Fund is an 'index fund' that invests in a particular sector or group of industries represented by a specified Select Sector Index. The companies included in each Select Sector Index are selected on the basis of general industry classification from a universe of companies defined by the Standard \& Poor's 500 Composite Stock Index (S\&P 500). The nine Select Sector Indexes (each a 'Select Sector Index') upon which the Funds are based together comprise all of the companies in the S\&P 500. The investment objective of each Fund is to provide investment results that, before expenses, correspond generally to the price and yield performance of publicly traded equity securities of companies in a particular sector or group of industries, as represented by a specified market sector index. The financial sector's ticker is XLF. Table A reports the XLF holdings before and after the crisis.

\section{B $\Delta$-Matched Spreads}

An alternative to strike-matching is constructing the option basket to ensure that the $\Delta \mathrm{s}$ of the two insurance schemes are equal. We first fix an option $\Delta$ to construct sector insurance positions. Next, we find strike prices $K_{i, j}\left(j=1,2, \ldots, N_{i}\right)$ for individual stocks, and the strike price $K_{i}$ for the index, to match the targeted $\Delta$ level. Next, we set $x_{i}$ to be the number of index options with strike $K_{i}$ such that the total dollar amount insured by the index equals the dollar amount insured by the basket:

$$
x_{i} K_{i}=\sum_{j=1}^{N_{i}} s_{i, j} K_{i, j} .
$$

The advantage of this approach is that both the index and individual options in the basket have the same moneyness.

Table B reports results for our the $\Delta$-matching approach to constructing the basket-index spread. Results are qualitatively and quantitatively similar to strike-matched results reported in the main text.

\section{Appendix Gaussian Model}

\section{C.1 Individual Firm returns}

An individual bank $j$ 's stock return is given by

$$
\begin{aligned}
r^{j} & =\mu^{j}-\lambda^{j} J^{a}+\sigma \epsilon^{j}, \\
J^{a} & =\min \left(J^{r}, \underline{J}\right), \quad J^{r} \sim \mathcal{N}\left(\theta_{r}, \delta_{r}^{2}\right)
\end{aligned}
$$

where the shock $\epsilon^{j}$ is an idiosyncratic shock which is standard normally distributed and i.i.d. over time and across firms. In contrast, the shock $J^{a}$ is an aggregate shock, also i.i.d. over time. The common shock is truncated by a government bailout for $\underline{J}<\infty$. The shocks $J^{r}$ and $\epsilon^{j}$ are orthogonal; $\epsilon^{j}$ is uncorrelated 
with the SDF. The process $J^{r}$ is correlated with the SDF; define $\sigma_{m, J}=\operatorname{Cov}\left(m, J^{r}\right)$ and

$$
\beta_{J}=\frac{\operatorname{Cov}\left(m, J^{r}\right)}{\operatorname{Var}\left(J^{r}\right)}=\frac{\sigma_{m, J}}{\delta_{r}^{2}} .
$$

Below we will use the fact that, since $m$ and $J^{r}$ are bivariate normal, which implies that:

$$
E\left[m \mid J^{r}\right]=E[m]+\beta_{J}\left(J^{r}-\theta_{r}\right), \text { and } V\left[m \mid J^{r}\right]=V[m]-\beta_{J} \sigma_{m, J}
$$

See Lemma 4 at the end of this appendix.

We are interested in computing the variance of returns and the covariance between a pair of returns. This will allow us to compute the volatility of returns and the correlation of returns. Two auxiliary results turn out to be useful:

$$
\begin{aligned}
E_{i}\left[J^{a}\right] & =E\left[\min \left(J^{r}, \underline{J}\right)\right]=E\left[J^{r} 1_{\left(J^{r}<\underline{J}\right)}\right]+\underline{J} E\left[1_{\left(J^{r} \geq \underline{J}\right)}\right] \\
& =\theta_{r} \Phi\left(\frac{\underline{J}-\theta_{r}}{\delta_{r}}\right)-\delta_{r} \phi\left(\frac{\underline{J}-\theta_{r}}{\delta_{r}}\right)+\underline{J} \Phi\left(\frac{\theta_{r}-\underline{J}}{\delta_{r i}}\right) \equiv \theta_{a}
\end{aligned}
$$

and

$$
\begin{aligned}
E_{i}\left[J^{a 2}\right] & =E\left[\min \left(J^{r}, \underline{J}\right)^{2}\right]=E\left[J^{r 2} 1_{\left(J^{r}<\underline{J}\right)}\right]+\underline{J}^{2} E\left[1_{\left(J^{r} \geq \underline{J}\right)}\right] \\
& =\left(\delta_{r}^{2}+\theta_{r}^{2}\right) \Phi\left(\frac{\underline{J}-\theta_{r}}{\delta_{r}}\right)-\delta_{r}\left(\underline{J}+\theta_{r}\right) \phi\left(\frac{\underline{J}-\theta_{r}}{\delta_{r}}\right)+\underline{J}^{2} \Phi\left(\frac{\theta_{r}-\underline{J}}{\delta_{r}}\right), \\
& \equiv \sigma_{a}^{2}+\theta_{a}^{2}
\end{aligned}
$$

The variance of returns is:

$$
\operatorname{Var}\left[r^{j}\right]=E\left[\left(r^{j}\right)^{2}\right]-\left[E\left[r^{j}\right]\right]^{2}=\sigma^{2}+\left(\lambda^{j}\right)^{2} \sigma_{a}^{2}
$$

Similarly, mean returns are given by:

$$
E\left[r^{j}\right]=\mu^{j}-\lambda^{j} \theta_{a}
$$

Note that if there is no bailout guarantee, $\theta_{a}=\theta_{r}$ and $\sigma_{a}^{2}=\delta_{r}^{2}$, so that

$$
\operatorname{Var}\left[r^{j}\right] \equiv \sigma_{n b}^{2}=\sigma^{2}+\left(\lambda^{j}\right)^{2} \delta_{r}^{2} \quad E\left[r^{j}\right]=\mu^{j}-\lambda^{j} \theta_{r}
$$

The covariance of a pair of different firms' returns $\left(r^{1}, r^{2}\right)$ is:

$$
\operatorname{Cov}\left[r_{i}^{1}, r_{i}^{2}\right]=E\left[r^{1} r^{2}\right]-\left[E\left[r^{1}\right] E\left[r^{2}\right]=\lambda^{1} \lambda^{2} \sigma_{a}^{2},\right.
$$

Define

$$
\chi=\theta_{r}+\sigma_{m, J}
$$


In order to get the equity risk premium for an individual stock, start from the Euler equation:

$$
\begin{aligned}
1= & E\left[\exp \left(m+\mu^{j}-\lambda^{j} J^{a}+\sigma \epsilon^{j}\right)\right] \\
= & \exp \left(\mu^{j}+.5 \sigma^{2}\right) E\left[\exp \left(m-\lambda^{j} J^{a}\right)\right] \\
= & \exp \left(\mu^{j}\right)\left\{E\left[\exp \left(m-\lambda^{j} J^{r}\right) 1_{\left(J^{r}<\underline{J}\right)}\right]+E\left[\exp \left(m-\lambda^{j} \underline{J}\right) 1_{\left(J^{r}>\underline{J}\right)}\right]\right\} \\
= & \exp \left(\mu^{j}+.5 \sigma^{2}\right)\left\{\Psi\left(1,-\lambda^{j} ; m, J^{r}\right) \Phi\left(\frac{\underline{J}-\chi+\lambda^{j} \delta_{r}^{2}}{\delta_{r}}\right)+\exp \left(-r^{f}-\lambda^{j} \underline{J}\right) \Phi\left(\frac{\theta_{r}-\underline{J}}{\delta_{r}}\right)\right\} \text { by Lemma } 1 \\
= & \exp \left(\mu^{j}-r^{f}+.5 \sigma^{2}\right) \\
& \times\left\{\exp \left(-\lambda^{j} \chi+.5\left(\lambda^{j}\right)^{2} \delta_{r}^{2}\right) \Phi\left(\frac{\underline{J}-\chi+\lambda^{j} \delta_{r}^{2}}{\delta_{r}}\right)+\exp \left(-\lambda^{j} \underline{J}\right) \Phi\left(\frac{\theta_{r}-\underline{J}}{\delta_{r}}\right)\right\}
\end{aligned}
$$

which implies that the expected return equals:

$$
\mu^{j}=r^{f}-.5 \sigma^{2}-\log \left\{\exp \left(-\lambda^{j} \chi+.5\left(\lambda^{j}\right)^{2} \delta_{r}^{2}\right) \Phi\left(\frac{\underline{J}-\chi+\lambda \delta_{r}^{2}}{\delta_{r}}\right)+\exp \left(-\lambda^{j} \underline{J}\right) \Phi\left(\frac{-\underline{J}}{\delta_{r}}\right)\right\} .
$$

In the no-bailout case, $\underline{J} \rightarrow+\infty$, and the equity risk premium (including Jensen term) becomes $\mu_{n b}^{j}-r^{f}+.5 \sigma_{n b}^{2}=\lambda^{j} \chi$.

\section{C.2 Aggregation to Sector}

We construct the value-weighted portfolio return of all stocks, the index, with portfolio weights $w$.

$$
r^{\text {index }}=\mu^{\text {index }}-J^{a}+\sigma^{\text {index }} \epsilon^{\text {index }},
$$

where $\epsilon^{\text {index }}$ is i.i.d. standard Normal, $w^{\prime} \lambda=1$, where $\mu^{\text {index }}=w^{\prime} \mu^{j}$, and where

$$
\sigma^{\text {index }}=\sqrt{w^{\prime} \sigma \sigma^{\prime} w} \approx 0
$$

If the number of firms is large and the weights are equal across firms, the last term equals zero. Note that we do not need to set it equal to zero.

Next, assume that diversification is complete so that $r^{\text {index }}=\mu^{\text {index }}-J^{a}$, and solve for $\mu^{\text {index }}$ from the Euler equation for the index return:

$$
\begin{aligned}
1 & =E\left[\exp \left(m+\mu^{i n d e x}-J^{a}\right)\right] \\
& =\exp \left(\mu^{\text {index }}\right)\left\{\Psi\left(1,-1 ; m, J^{r}\right) \Phi\left(\frac{\underline{J}-\chi+\delta_{r}^{2}}{\delta_{r}}\right)+\exp \left(-r^{f}-\underline{J}\right) \Phi\left(\frac{\theta_{r}-\underline{J}}{\delta_{r}}\right)\right\} \text { by Lemma } 1 \\
& =\exp \left(\mu^{\text {index }}-r^{f}\right)\left\{\exp \left(-\chi+\frac{\delta_{r}^{2}}{2}\right) \Phi\left(\frac{\underline{J}-\chi+\delta_{r}^{2}}{\delta_{r}}\right)+\exp (-\underline{J}) \Phi\left(\frac{\theta_{r}-\underline{J}}{\delta_{r}}\right)\right\}
\end{aligned}
$$

which implies

$$
\mu^{i n d e x}=r^{f}-\log \left\{\exp \left(-\chi+\frac{\delta_{r}^{2}}{2}\right) \Phi\left(\frac{\underline{J}-\chi+\delta_{r}^{2}}{\delta_{r}}\right)+\exp (-\underline{J}) \Phi\left(\frac{\theta_{r}-\underline{J}}{\delta_{r}}\right)\right\} .
$$

In the no-bailout case, this gives $\mu_{n b}^{i n d e x}=r^{f}-\frac{\delta_{r}^{2}}{2}+\chi$. 


\section{Valuing Options}

The main technical contribution of the paper is to price options in the presence of a bailout guarantee. We are interested in the price per dollar invested in a put option (cost per dollar insured) on a bank stock. For simplicity, we assume that the option has a one-period maturity and is of the European type. We denote the put price by Put:

$$
\text { Put } t_{t}=E_{t}\left[M_{t+1}\left(K-R_{t+1}\right)^{+}\right] \text {, }
$$

where the strike price $K$ is expressed as a fraction of a dollar (that is, $K=1$ is the ATM option). The option value in state $i$ on stock $j$ is:

$$
\operatorname{Put}^{j}=E\left[M\left(K-R^{j}\right)^{+}\right]=-E\left[\exp \left(m+r^{j}\right) 1_{k>r^{j}}\right]+K E\left[\exp (m) 1_{k>r^{j}}\right]=-V_{1}+V_{2}
$$

We now compute this in terms of the underlying structural parameters. Define $\tilde{r}=\mu+\sigma \epsilon$ and $r=$ $\tilde{r}-\lambda \min \left(J^{r}, \underline{J}\right)$, where we omit the dependence on $j$ for ease of notation. Our derivation below exploits the normality of $m$ and $\tilde{r}$, which are conditionally uncorrelated.

\section{First term $V_{1}$}

$$
\begin{aligned}
V_{1} & =E\left[\exp (m+r) 1_{k>r} 1_{J^{r}<\underline{J}}\right]+E\left[\exp (m+r) 1_{k>r} 1_{J^{r}>\underline{J}}\right] \\
& =E\left[\exp \left(m+\tilde{r}-\lambda J^{r}\right) 1_{k>r} 1_{J^{r}<\underline{J}}\right]+E\left[\exp (m+\tilde{r}-\lambda \underline{J}) 1_{k>r} 1_{J^{r}>\underline{J}}\right] \\
& =V_{11}+V_{12}
\end{aligned}
$$

The first term $V_{11}$ can be solved as follows:

$$
\begin{aligned}
& V_{11}=E\left[\exp \left(m+\tilde{r}-\lambda J^{r}\right) 1_{k>r} 1_{J^{r}<\underline{J}}\right] \\
& =E\left[E\left\{\exp \left(m+\tilde{r}-\lambda J^{r}\right) 1_{k+\lambda J^{r}>\tilde{r}} \mid J^{r}\right\} 1_{J^{r}<\underline{J}}\right] \\
& =E\left[E\left\{\exp (m+\tilde{r}) 1_{k+\lambda J^{r}>\tilde{r}} \mid J^{r}\right\} \exp \left(-\lambda J^{r}\right) 1_{J^{r}<\underline{J}}\right] \\
& =E\left\{E\left[\exp (m) \mid J^{r}\right] E\left[\exp (\tilde{r}) 1_{k+\lambda J^{r}>\tilde{r}} \mid J^{r}\right] E\left[\exp \left(-\lambda J^{r}\right) 1_{J^{r}<\underline{J}} \mid J^{r}\right]\right\} \\
& =E\left\{\exp \left(E\left[m \mid J^{r}\right]+.5 V\left[m \mid J^{r}\right]\right) E\left[\exp (\tilde{r}) 1_{k+\lambda J^{r}>\tilde{r}} \mid J^{r}\right] \exp \left(-\lambda J^{r}\right) 1_{J^{r}<\underline{J}}\right\} \\
& =E\left\{\exp \left(E[m]+\beta_{J}\left(J^{r}-\theta_{r}\right)+.5 V[m]-.5 \beta_{J} \sigma_{m, J}\right) E\left[\exp (\tilde{r}) 1_{k+\lambda J^{r}>\tilde{r}} \mid J^{r}\right] \exp \left(-\lambda J^{r}\right) 1_{J^{r}<\underline{J}}\right\} \\
& =\Psi(1 ; m) \exp \left(-\beta_{J} \theta_{r}-.5 \beta_{J} \sigma_{m, J}\right) E\left\{E\left[\exp (\tilde{r}) 1_{k+\lambda J^{r}>\tilde{r}} \mid J^{r}\right] \exp \left(\left[\beta_{J}-\lambda\right] J^{r}\right) 1_{J^{r}<\underline{J}}\right\} \\
& =\Psi(1 ; m) \Psi(1 ; \tilde{r}) \exp \left(-\beta_{J} \theta_{r}-.5 \beta_{J} \sigma_{m, J}\right) E\left\{\Phi\left(\phi_{0}+\phi_{1} J^{r}\right) \exp \left(\left[\beta_{J}-\lambda\right] J^{r}\right) 1_{J^{r}<J}\right\} \text { by Lemma } 1 \\
& =\Psi(1 ; m) \Psi(1 ; \tilde{r}) \exp \left(-\beta_{J} \theta_{r}-.5 \beta_{J} \sigma_{m, J}+.5\left[\beta_{J}-\lambda\right]^{2} \delta_{r}^{2}+\left[\beta_{J}-\lambda\right] \theta_{r}\right) \\
& \times \Phi\left(\frac{\phi_{0}-t_{1}}{\sqrt{1+\phi_{1}^{2} \delta_{r}^{2}}}, \frac{\underline{J}-t_{2}}{\delta_{r}} ; \rho\right) \text { by Lemma } 2 \\
& =\Psi(1 ; m) \Psi(1 ; \tilde{r}) \exp \left(.5 \lambda^{2} \delta_{r}^{2}-\lambda\left[\sigma_{m, J}+\theta_{r}\right]\right) \Phi\left(\frac{\phi_{0}-t_{1}}{\sqrt{1+\phi_{1}^{2} \delta_{r}^{2}}}, \frac{\underline{J}-t_{2}}{\delta_{r}} ; \rho\right)
\end{aligned}
$$

where $\phi_{1}=\frac{\lambda}{\sigma}, \phi_{0}=\frac{\phi_{1}}{\lambda}\left(k-\mu-\sigma^{2}\right), t_{2}=\theta_{r}+\sigma_{m, J}-\lambda \delta_{r}^{2}, t_{1}=-\phi_{1} t_{2}$, and $\rho=\frac{-\phi_{1} \delta_{r}}{\sqrt{1+\phi_{1}^{2} \delta_{r}^{2}}}$. We have used fact that $m$ and $J^{r}$ are jointly normal to calculate the conditional moments $E\left[m \mid J^{r}\right]$ and $V\left[m \mid J^{r}\right]$, as discussed above. 
Next, we turn to $V_{12}$ :

$$
\begin{aligned}
V_{12} & =E\left[\exp (m+\tilde{r}-\lambda \underline{J}) 1_{k>r} 1_{J^{r}>\underline{J}}\right] \\
& =\exp (-\lambda \underline{J}) E\left\{E\left[\exp (m) \mid J^{r}\right] 1_{J^{r}>\underline{J}}\right\} E\left[\exp (\tilde{r}) 1_{k+\lambda \underline{J}>\tilde{r}]}\right. \\
& =\exp \left(-\beta_{J} \theta_{r}-.5 \beta_{J} \sigma_{m, J}-\lambda \underline{J}\right) \Psi(1 ; m) \Psi(1 ; \tilde{r}) \Phi\left(\frac{\lambda \underline{J}+k-\mu-\sigma^{2}}{\sigma}\right) E\left[\exp \left(\beta_{J} J^{r}\right) 1_{J^{r}>\underline{J}}\right] \\
& =\exp (-\lambda \underline{J}) \Psi(1 ; m) \Psi(1 ; \tilde{r}) \Phi\left(\frac{\lambda \underline{J}+k-\mu-\sigma^{2}}{\sigma}\right)\left[1-\Phi\left(\frac{\underline{J}-\theta_{r}-\sigma_{m, J}}{\delta_{r}}\right)\right] \text { by Lemma } 1 \\
& =\exp (-\lambda \underline{J}) \Psi(1 ; m) \Psi(1 ; \tilde{r}) \Phi\left(\frac{\lambda \underline{J}+k-\mu-\sigma^{2}}{\sigma}\right) \Phi\left(\frac{-\underline{J}+\theta_{r}+\sigma_{m, J}}{\delta_{r}}\right)
\end{aligned}
$$

\section{Second term $V_{2}$}

$$
\begin{aligned}
V_{2} & =K E\left[\exp (m) 1_{k>r}\right] \\
& =K E\left[\exp (m) 1_{k>r} 1_{J^{r}<\underline{J}}\right]+K E\left[\exp (m) 1_{k>r} 1_{J^{r}>J}\right] \\
& =V_{21}+V_{22} .
\end{aligned}
$$

The first term $V_{21}$ can be solved as follows:

$$
\begin{aligned}
V_{21} & =K E\left[\exp (m) 1_{k>r} 1_{J^{r}<J}\right] \\
& =K E\left[E\left\{\exp (m) 1_{k+\lambda J^{r}>\tilde{r}} \mid J^{r}\right\} 1_{J^{r}<J}\right] \\
& =K \Psi(1 ; m) \exp \left(-\beta_{J} \theta_{r}-.5 \beta_{J} \sigma_{m, J}\right) E\left[\Phi\left(\phi_{0}+\phi_{1} J^{r}\right) \exp \left(\beta_{J} J^{r}\right) 1_{J^{r}<J}\right] \text { by Lemma } 1 \\
& =K \Psi(1 ; m) \Phi\left(\frac{\phi_{0}-t_{1}}{\sqrt{1+\phi_{1}^{2} \delta_{r}^{2}}}, \frac{J-t_{2}}{\delta_{r}} ; \rho\right) \text { by Lemma } 2
\end{aligned}
$$

where $\phi_{1}=\frac{\lambda}{\sigma_{d}}, \phi_{0}=\frac{\phi_{1}}{\lambda}(k-\mu), t_{2}=\theta_{r}+\sigma_{m, J}, t_{1}=-\phi_{1} t_{2}, \rho=\frac{-\phi_{1} \delta_{r}}{\sqrt{1+\phi_{1}^{2} \delta_{r}^{2}}}$.

Finally, we turn to $V_{22}$ :

$$
\begin{aligned}
V_{22} & =K E\left[\exp (m) 1_{k>r} 1_{J^{r}>\underline{J}}\right] \\
& =K E\left[\exp (m) 1_{\left.k+\lambda \underline{J}>\tilde{r} 1_{J^{r}>\underline{J}}\right]}\right. \\
& =K E\left\{E\left[\exp (m) \mid J^{r}\right] 1_{J^{r}>\underline{J}}\right\} E\left[1_{k+\lambda \underline{J}>\tilde{r}}\right] \\
& =K \exp \left(-\beta_{J} \theta_{r}-.5 \beta_{J} \sigma_{m, J}\right) \Psi(1 ; m) \Phi\left(\frac{\lambda \underline{J}+k-\mu}{\sigma}\right) E\left[\exp \left(\beta_{J} J^{r}\right) 1_{J^{r}>\underline{J}}\right] \\
& =K \Psi(1 ; m) \Phi\left(\frac{\lambda \underline{J}+k-\mu}{\sigma}\right)\left[1-\Phi\left(\frac{\underline{J}-\theta_{r}-\sigma_{m, J}}{\delta_{r}}\right)\right] \text { by Lemma } 1 \\
& =K \Psi(1 ; m) \Phi\left(\frac{\lambda \underline{J}+k-\mu}{\sigma}\right) \Phi\left(\frac{-\underline{J}+\theta_{r}+\sigma_{m, J}}{\delta_{r}}\right) .
\end{aligned}
$$

Combining Terms Note that $\Psi(1 ; m)=\exp \left(-r_{t}^{f}\right)$ and that $\Psi(1 ; \tilde{r})=\exp \left(\mu_{r}+.5 \sigma^{2}\right)$ which is the expected $\log$ stock return adjusted for a Jensen term. Note that the Jensen term only involves the idiosyncratic risk. The correlation coefficient is $\rho=\frac{-\lambda \delta_{r}}{\sqrt{\sigma^{2}+\lambda^{2} \delta_{r}^{2}}}$. Recall the definitions:

$$
\chi=\theta_{r}+\sigma_{m, J} \quad \text { and } \quad \sigma_{n b}^{2}=\sigma^{2}+\lambda^{2} \delta_{r}^{2} .
$$


Combining the four terms, we get that the put price on an individual stock is given by (dependence on $j$ suppressed):

$$
\begin{aligned}
\text { Put }= & -\exp \left(\mu-r^{f}+.5 \sigma^{2}\right)\left\{\exp \left(-\lambda \chi+.5 \lambda^{2} \delta_{r}^{2}\right) \Phi\left(\frac{k-\mu+\lambda \chi-\sigma_{n b}^{2}}{\sigma_{n b}}, \frac{\underline{J}-\chi+\lambda \delta_{r}^{2}}{\delta_{r}} ; \rho\right)\right. \\
& \left.+\exp (-\lambda \underline{J}) \Phi\left(\frac{k-\mu-\sigma^{2}+\lambda \underline{J}}{\sigma}\right) \Phi\left(\frac{-\underline{J}+\chi}{\delta_{r}}\right)\right\} \\
& +K \exp \left(-r_{t}^{f}\right)\left\{\Phi\left(\frac{k-\mu+\lambda \chi}{\sigma_{n b}}, \frac{\underline{J}-\chi}{\delta_{r}} ; \rho\right)+\Phi\left(\frac{k-\mu+\lambda \underline{J}}{\sigma}\right) \Phi\left(\frac{-\underline{J}+\chi}{\delta_{r}}\right)\right\}
\end{aligned}
$$

Comparison with Black-Scholes To compare with Black-Scholes, set $\underline{J}=+\infty$. This implies, along with $\mu_{n b}^{j}-r^{f}+.5 \sigma_{n b}^{2}=\lambda^{j} \chi$, that

$$
P u t=-\Phi\left(\frac{k-r^{f}-.5 \sigma_{n b}^{2}}{\sigma_{n b}}\right)+K \exp \left(-r_{t}^{f}\right) \Phi\left(\frac{k-r^{f}+.5 \sigma_{n b}^{2}}{\sigma_{n b}}\right) .
$$

Hence, our expression collapses to the standard Black-Scholes price for a put option in the absence of a bailout guarantee.

The Index The index option price is a simple case of the general option pricing formula with $\mu^{j}=$ $\mu^{\text {index }}, \lambda^{j}=1$ and with $\sigma^{j}=\sigma^{\text {index }}$. Under the additional assumption that $\sigma^{\text {index }}=0$, the derivation simplifies somewhat. The variable $\tilde{r}$ is then no longer a random variable, but a constant. The four terms of the put option formula become

$$
\begin{aligned}
& V_{11}^{\text {index }}=\exp \left(\mu^{\text {index }}-r^{f}+.5 \delta_{r}^{2}-\chi\right)\left\{\Phi\left(\frac{\underline{J}-\chi+\delta_{r}^{2}}{\delta_{r}}\right)-\Phi\left(\frac{\mu^{\text {index }}-k-\chi+\delta_{r}^{2}}{\delta_{r}}\right)\right\} \\
& V_{12}^{\text {index }}=\exp \left(\mu^{\text {index }}-r^{f}-\underline{J}\right) \Phi\left(\frac{-\underline{J}+\chi}{\delta_{r}}\right) \\
& V_{21}^{\text {index }}=K \exp \left(-r^{f}\right)\left\{\Phi\left(\frac{\underline{J}-\chi}{\delta_{r}}\right)-\Phi\left(\frac{\mu^{\text {index }}-k-\chi}{\delta_{r}}\right)\right\} \\
& V_{22}^{\text {index }}=K \exp \left(-r^{f}\right) \Phi\left(\frac{-\underline{J}+\chi}{\delta_{r}}\right)
\end{aligned}
$$

Combining terms,

$$
\begin{aligned}
\text { Put }^{\text {index }}= & -\exp \left(\mu^{\text {index }}-r^{f}\right)\left\{\exp \left(.5 \delta_{r}^{2}-\chi\right)\left[\Phi\left(\frac{\underline{J}-\chi+\delta_{r}^{2}}{\delta_{r}}\right)-\Phi\left(\frac{\mu^{\text {index }}-k-\chi+\delta_{r}^{2}}{\delta_{r}}\right)\right]\right. \\
& \left.+\exp (-\underline{J}) \Phi\left(\frac{-\underline{J}+\chi}{\delta_{r}}\right)\right\}+K \exp \left(-r^{f}\right) \Phi\left(\frac{k-\mu_{r}^{\text {index }}+\chi}{\delta_{r}}\right)
\end{aligned}
$$

Note that this formula only holds if $\mu^{\text {index }}<k+\underline{J}$. If instead $\mu^{\text {index }}>k+\underline{J}$, then $P u t^{i n d e x}=0$.

\section{E How to Operationalize}

We need each of the inputs to formula (7). The six-step procedure below is for a given bailout level $\underline{J}$. 
First, and without loss of generality, we set $\theta_{r}=0$, which makes $J^{r}$ a mean-zero shock. Also, the formula requires a zero-coupon risk-free rate $r^{f}$ which is readily available in the OptionMetrics data at daily frequency.

Second, we can recover estimates for $\sigma_{n b}$ and $\delta_{r}$ from the variance of an individual stock return,

$$
\left(\sigma^{j}\right)^{2}=\left(\lambda^{j}\right)^{2} \sigma_{a}^{2}+\sigma^{2},
$$

and from the variance of the index return,

$$
\left(\sigma^{\text {index }}\right)^{2}=\sigma_{a}^{2}+w^{\prime} \sigma_{d} \sigma_{d}^{\prime} w \approx \sigma_{a}^{2}
$$

where $w$ are the weights of the stocks in the index. When the number of firms is large and index components are about equally weighted, the last term is approximately zero. These two variances can be estimated at a daily frequency.

Third, abstracting from heterogeneity in $\lambda$, the correlation between two stocks in the index is $\rho\left(r^{k}, r^{j}\right)=$ $\frac{\lambda^{2} \sigma_{a}^{2}}{\lambda^{2} \sigma_{a}^{2}+\sigma^{2}}$. The correlation should be estimated over the same (rolling) window as the individual and aggregate variance. Now, we can back out an estimate for $\lambda$ and $\sigma_{d}^{2}$ from the correlation, the variance of the individual return and the variance of the index return. We have $\sigma_{d}^{2}=\sigma_{r}^{2}-\left(\lambda^{j}\right)^{2} \sigma_{a}^{2}$ and $\lambda=\frac{\sigma_{r} \sqrt{\rho_{i, j}}}{\sigma_{a}}$.

Fourth, the moments of the aggregate truncated shock derived above imply the following non-linear equation, which we can solve based on observables to arrive at an estimate for the jump variance $\delta_{r}$ :

$$
\sigma_{a}^{2}=\delta_{r}^{2} \Phi\left(\frac{\underline{J}}{\delta_{r}}\right)-\delta_{r} \underline{J} \phi\left(\frac{\underline{J}}{\delta_{r}}\right)+\underline{J}^{2} \Phi\left(\frac{-\underline{J}}{\delta_{r}}\right)-\delta_{r}^{2} \phi\left(\frac{\underline{J}}{\delta_{r}}\right)^{2}-\underline{J}^{2} \Phi\left(\frac{-\underline{J}}{\delta_{r}}\right)^{2}+2 \delta_{r} \underline{J} \phi\left(\frac{\underline{J}}{\delta_{r}}\right) \Phi\left(\frac{-\underline{J}}{\delta_{r}}\right) .
$$

Finally, we must estimate the expected log index return. To do so, we rely on the equity risk premium lower bound derived in Martin's (2011) simple variance swap framework. He shows that the following bound obtains under weak assumptions:

$$
\exp \left(r^{f}\right) E\left[\exp \left(r^{\text {index }}\right)-\exp \left(r^{f}\right)\right] \geq S V I X^{2} .
$$

For our estimate, we assume that this bound holds with equality. Next, we make the Jensen inequality adjustment

$$
\log E\left[\exp \left(r^{\text {index }}\right)\right]=\mu^{\text {index }}+.5 \sigma_{a}^{2} .
$$

This relationship is exact in the absence of a bailout $(\underline{J}=\infty)$. When $J^{a}$ is truncated, normality is violated and the equality in (8) is an approximation. The expected return based on $S V I X$ and the previously discussed inputs is then calculated as

$$
\mu^{i n d e x}=\log \left(\frac{S V I X^{2}}{\exp \left(r^{f}\right)}+\exp \left(r^{f}\right)\right)-\frac{\sigma_{a}^{2}}{2} .
$$

Our calculation of $S V I X$ for this step uses financial sector index options with $T T M=30$. Our construction follows Martin (2011), which effectively forms an equally weighted portfolio of index calls and puts with varying strikes. 


\section{F Auxiliary Lemmas}

Lemma 1. Let $x \sim N\left(\mu_{x}, \sigma_{x}^{2}\right)$ and $y \sim N\left(\mu_{y}, \sigma_{y}^{2}\right)$ with $\operatorname{Corr}(x, y)=\rho_{x y}$. Then

$E\left[\exp (a x+b y) 1_{d<y<c}\right]=\Psi(a, b ; x, y)\left\{\Phi\left(\frac{c-\mu_{y}-b \sigma_{y}^{2}-a \rho_{x y} \sigma_{x} \sigma_{y}}{\sigma_{y}}\right)-\Phi\left(\frac{d-\mu_{y}-b \sigma_{y}^{2}-a \rho_{x y} \sigma_{x} \sigma_{y}}{\sigma_{y}}\right)\right\}$

where $\Psi(a, b ; x, y)=\exp \left(a \mu_{x}+b \mu_{y}+\frac{a^{2} \sigma_{x}^{2}}{2}+\frac{b^{2} \sigma_{y}^{2}}{2}+a b \rho_{x y} \sigma_{x} \sigma_{y}\right)$ is the bivariate normal moment-generating function of $x$ and $y$ evaluated at $(a, b)$.

Proof. Lemma 1 First, note that $x \mid y \sim N\left(\mu_{x}+\frac{\rho_{x y} \sigma_{x}}{\sigma_{y}}\left[y-\mu_{y}\right], \sigma_{x}^{2}\left(1-\rho_{x y}^{2}\right)\right)$, therefore

$$
E[\exp (a x) \mid y]=Q \exp \left(\frac{a \rho_{x y} \sigma_{x}}{\sigma_{y}} y\right)
$$

where $Q=\exp \left(a \mu_{x}-\frac{a \rho_{x y} \sigma_{x} \mu_{y}}{\sigma_{y}}+\frac{a^{2} \sigma_{x}^{2}\left(1-\rho_{x y}^{2}\right)}{2}\right)$. Denote $\Gamma=E\left[\exp (a x+b y) 1_{d<y<c}\right]$, then:

$$
\begin{aligned}
\Gamma & =E\left[E\{\exp (a x) \mid y\} \exp (b y) 1_{d<y<c}\right] \\
& =Q E\left[\exp \left(y\left\{\frac{a \rho_{x y} \sigma_{x}}{\sigma_{y}}+b\right\}\right) 1_{d<y<c}\right] \\
& =Q \int_{d}^{c} \exp \left(y\left\{\frac{a \rho_{x y} \sigma_{x}}{\sigma_{y}}+b\right\}\right) d F(y) \\
& =Q \int_{d}^{c} \exp \left(y\left\{\frac{a \rho_{x y} \sigma_{x}}{\sigma_{y}}+b+\frac{\mu_{y}}{\sigma_{y}^{2}}\right\}-\frac{y^{2}}{2 \sigma_{y}^{2}}-\frac{\mu_{y}^{2}}{2 \sigma_{y}^{2}}\right) \frac{d y}{\sigma_{y} \sqrt{2 \pi}}
\end{aligned}
$$

Complete the square

$$
\begin{aligned}
= & Q \exp \left(\frac{\sigma_{y}^{2}}{2} \sigma_{y}\left\{\frac{a \rho_{x y} \sigma_{x}}{\sigma_{y}}+b\right\}^{2}+\mu_{y}\left\{\frac{a \rho_{x y} \sigma_{x}}{\sigma_{y}}+b\right\}\right) \int_{d}^{c} \exp \left(-\frac{\left[y-\sigma_{y}^{2}\left\{\frac{a \rho_{x y} \sigma_{x}}{\sigma_{y}}+b+\frac{\mu_{y}}{\sigma_{y}^{2}}\right\}\right]^{2}}{2 \sigma_{y}^{2}}\right) \frac{d y}{\sigma_{y} \sqrt{2 \pi}} \\
& \text { Substitute } u=\frac{y-\sigma_{y}^{2}\left\{\frac{a \rho_{x y} \sigma_{x}}{\sigma_{y}}+b+\frac{\mu_{y}}{\sigma_{y}^{2}}\right\}}{\sigma_{y}}, d u \sigma_{y}=d y
\end{aligned}
$$$$
\begin{aligned}
= & \exp \left(a \mu_{x}+\frac{a^{2} \sigma_{x}^{2}\left(1-\rho_{x y}^{2}\right)}{2}+\frac{\sigma_{y}^{2}}{2}\left\{\frac{a \rho_{x y} \sigma_{x}}{\sigma_{y}}+b\right\}^{2}+b \mu_{y}\right) \\
& \times\left\{\Phi\left(\frac{c-\mu_{y}-b \sigma_{y}^{2}-a \rho_{x y} \sigma_{x} \sigma_{y}}{\sigma_{y}}\right)-\Phi\left(\frac{d-\mu_{y}-b \sigma_{y}^{2}-a \rho_{x y} \sigma_{x} \sigma_{y}}{\sigma_{y}}\right)\right\}
\end{aligned}
$$

Lemma 2. Let $x \sim N\left(\mu_{x}, \sigma_{x}^{2}\right)$, then

$$
E\left[\Phi\left(b_{0}+b_{1} x\right) \exp (a x) 1_{x<c}\right]=\Phi\left(\frac{b_{0}-t_{1}}{\sqrt{1+b_{1}^{2} \sigma_{x}^{2}}}, \frac{c-t_{2}}{\sigma_{x}} ; \rho\right) \exp \left(z_{1}\right)
$$

where $t_{1}=-b_{1} t_{2}, t_{2}=a \sigma_{x}^{2}+\mu_{x}, z_{1}=\frac{a^{2} \sigma_{x}^{2}}{2}+a \mu_{x}, \rho=\frac{-b_{1} \sigma_{x}}{\sqrt{1+b_{1}^{2} \sigma_{x}^{2}}}$, and $\Phi(\cdot, \cdot ; \rho)$ is the cumulative density function (CDF) of a bivariate standard normal with correlation parameter $\rho$. 
Proof. Lemma 2 Denote $\Omega=E\left[\Phi\left(b_{0}+b_{1} x\right) \exp (a x) 1_{x<c}\right]$, then:

$$
\begin{aligned}
\Omega & =\int_{-\infty}^{c} \int_{-\infty}^{b_{0}+b_{1} x} \exp (a x) d F(v) d F(x) \\
& =\int_{-\infty}^{c} \int_{-\infty}^{b_{0}+b_{1} x} \exp \left(a x-\frac{v^{2}}{2}-\frac{\left[x-\mu_{x}\right]^{2}}{2 \sigma_{x}^{2}}\right) \frac{d v d x}{\sigma_{x} 2 \pi}
\end{aligned}
$$

Substitute $v=u+b_{1} x, d v=d u$

$$
\begin{aligned}
& =\int_{-\infty}^{c} \int_{-\infty}^{b_{0}} \exp \left(a x-\frac{\left(u+b_{1} x\right)^{2}}{2}-\frac{\left[x-\mu_{x}\right]^{2}}{2 \sigma_{x}^{2}}\right) \frac{d u d x}{\sigma_{x} 2 \pi} \\
& =\int_{-\infty}^{c} \int_{-\infty}^{b_{0}} \exp \left(-\frac{u^{2}}{2}-x^{2}\left(\frac{1}{2 \sigma_{x}^{2}}+\frac{b_{1}^{2}}{2}\right)-b_{1} u x+0 u+x\left(a+\frac{\mu_{x}}{\sigma_{x}^{2}}\right)-\frac{\mu_{x}^{2}}{2 \sigma_{x}^{2}}\right) \frac{d u d x}{\sigma_{x} 2 \pi}
\end{aligned}
$$

Complete the square in two variables using Lemma 3

$$
\begin{aligned}
& =\int_{-\infty}^{c} \int_{-\infty}^{b_{0}} \exp \left\{\left(\begin{array}{c}
u-t_{1} \\
x-t_{2}
\end{array}\right)^{\prime}\left(\begin{array}{ll}
s 1 & s 2 \\
s 2 & s 3
\end{array}\right)\left(\begin{array}{c}
u-t_{1} \\
x-t_{2}
\end{array}\right)+z_{1}\right\} \frac{d u d x}{\sigma_{x} 2 \pi} \\
& =\int_{-\infty}^{c} \int_{-\infty}^{b_{0}} \exp \left(-\frac{1}{2}(U-T)^{\prime}(-2 S)(U-T)+z_{1}\right) \frac{d u d x}{\sigma_{x} 2 \pi}
\end{aligned}
$$

where $U=(u, x), T=\left(t_{1}, t_{2}\right),-2 S=\left(\begin{array}{cc}1 & b_{1} \\ b_{1} & b_{1}^{2}+\frac{1}{\sigma_{x}^{2}}\end{array}\right),(-2 S)^{-1}=\left(\begin{array}{cc}1+b_{1}^{2} \sigma_{x}^{2} & -b_{1} \sigma_{x}^{2} \\ -b_{1} \sigma_{x}^{2} & \sigma_{x}^{2}\end{array}\right)$. This is the $\mathrm{CDF}$ for $U \sim N\left(T,(-2 S)^{-1}\right)$. Let $w_{1}=\frac{u-t_{1}}{\sqrt{1+b_{1}^{2} \sigma_{x}^{2}}}, w_{2}=\frac{x-t_{2}}{\sigma_{x}}$, and $\Sigma=\left(\begin{array}{cc}1 & \rho \\ \rho & 1\end{array}\right)$ with $\rho=\frac{-b_{1} \sigma_{x}}{\sqrt{1+b_{1}^{2} \sigma_{x}^{2}}}$. We have that $W^{\prime}=\left(w_{1}, w_{2}\right) \sim N(0, \Sigma)$. Also, $d u=d w_{1} \sqrt{1+b_{1}^{2} \sigma_{x}^{2}}$ and $d x=d w_{2} \sigma_{x}$.

$$
\begin{aligned}
\Omega & =\exp \left(z_{1}\right)\left\{\int_{-\infty}^{\frac{c-t_{2}}{\sigma_{x}}} \int_{-\infty}^{\frac{b_{0}-t_{1}}{\sqrt{1+b_{1}^{2} \sigma_{x}^{2}}}} \exp \left(-\frac{1}{2} W^{\prime} \Sigma^{-1} W\right) \frac{d w_{1} d w_{2}}{2 \pi \sqrt{1-\rho^{2}}}\right\} \sqrt{1+b_{1}^{2} \sigma_{x}^{2}} \sqrt{1-\rho^{2}} \\
& =\Phi\left(\frac{b_{0}-t_{1}}{\sqrt{1+b_{1}^{2} \sigma_{x}^{2}}}, \frac{c-t_{2}}{\sigma_{x}} ; \rho\right) \exp \left(z_{1}\right)
\end{aligned}
$$

where we used that $\sqrt{1+b_{1}^{2} \sigma_{x}^{2}} \sqrt{1-\rho^{2}}=1$, and where completing the square implies $t_{1}=-b_{1} t_{2}, t_{2}=$ $a \sigma_{x}^{2}+\mu_{x}, s_{1}=-.5, s_{2}=-.5 b_{1}, s_{3}=-.5 b_{1}^{2}-\frac{1}{2 \sigma_{x}^{2}}$, and $z_{1}=\frac{a^{2} \sigma_{x}^{2}}{2}+a \mu_{x}$ by application of Lemma 3 .

Lemma 3. Bivariate Complete Square

$$
A x^{2}+B y^{2}+C x y+D x+E y+F=\left(\begin{array}{l}
x-t_{1} \\
y-t_{2}
\end{array}\right)^{\prime}\left(\begin{array}{ll}
s_{1} & s_{2} \\
s_{2} & s_{3}
\end{array}\right)\left(\begin{array}{l}
x-t_{1} \\
y-t_{2}
\end{array}\right)+z_{1}
$$

where

$$
\begin{array}{ll}
t_{1}=-(2 B D-C E) /\left(4 A B-C^{2}\right) & s_{1}=A \\
t_{2}=-(2 A E-C D) /\left(4 A B-C^{2}\right) & s_{2}=C / 2 \\
z_{1}=F-\frac{B D^{2}-C D E+A E^{2}}{4 A B-C^{2}} & s_{3}=B .
\end{array}
$$


Lemma 4. Let $Z \sim N\left(\mu, \sigma^{2}\right)$ and define $\phi=\phi\left(\frac{b-\mu}{\sigma}\right)$ and $\Phi=\Phi\left(\frac{b-\mu}{\sigma}\right)$. Then

$$
\begin{aligned}
E\left[Z 1_{Z<b}\right] & =\mu \Phi-\sigma \phi \\
E\left[Z^{2} 1_{Z<b}\right] & =\left(\sigma^{2}+\mu^{2}\right) \Phi-\sigma(b+\mu) \phi
\end{aligned}
$$

Proof.

$$
E\left[Z 1_{Z<b}\right]=E[Z \mid Z<b] \operatorname{Pr}(Z<b)=\left(\mu-\frac{\sigma \phi}{\Phi}\right) \Phi=\mu \Phi-\sigma \phi
$$

The second result is shown similarly:

$$
\begin{aligned}
E\left[Z^{2} 1_{Z<b}\right] & =E\left[Z^{2} \mid Z<b\right] \operatorname{Pr}(Z<b) \\
& =\left(\operatorname{Var}\left[Z^{2} \mid Z<b\right]+E[Z \mid Z<b]^{2}\right) \operatorname{Pr}(Z<b) \\
& =\left(\sigma^{2}-\frac{\sigma(b-\mu) \phi}{\Phi}-\sigma^{2} \frac{\phi^{2}}{\Phi^{2}}+\left[\mu-\frac{\sigma \phi}{\Phi}\right]^{2}\right) \Phi \\
& =\left(\sigma^{2}+\mu^{2}\right) \Phi-\sigma(b+\mu) \phi .
\end{aligned}
$$


Table A: Top 40 Holdings of the Financial Sector Index XLF

\begin{tabular}{|c|c|c|c|c|}
\hline & \multicolumn{2}{|l|}{$12 / 30 / 2010$} & \multicolumn{2}{|l|}{$07 / 30 / 2007$} \\
\hline & Name & Weighting & Name & Weighting \\
\hline 1 & JPMorgan Chase & 9.01 & Citigroup & 11.1 \\
\hline 2 & Wells Fargo & 8.86 & Bank of America & 10.14 \\
\hline 3 & Citigroup & 7.54 & AIG & 8.02 \\
\hline 4 & Berkshire Hathaway & 7.52 & JPMorgan Chase & 7.25 \\
\hline 5 & Bank of America & 7.30 & Wells Fargo & 5.44 \\
\hline 6 & Goldman Sachs & 4.66 & Wachovia & 4.35 \\
\hline 7 & U.S. Bancorp & 2.82 & Goldman Sachs & 3.71 \\
\hline 8 & American Express & 2.44 & American Express & 3.35 \\
\hline 9 & Morgan Stanley & 2.25 & Morgan Stanley \& C & 3.25 \\
\hline 10 & MetLife & 2.21 & Merrill Lynch & 3.11 \\
\hline 11 & Bank of New York Mellon & 2.04 & Federal National Mortgage & 2.81 \\
\hline 12 & PNC Financial Services & 1.75 & US Bancopr & 2.51 \\
\hline 13 & Simon Property & 1.60 & Bank of New York Mellon & 2.32 \\
\hline 14 & Prudential & 1.56 & Metlife & 2.15 \\
\hline 15 & AFLAC & 1.45 & Prudential & 2.00 \\
\hline 16 & Travelers & 1.39 & Federal Home Loan Mortgage & 1.83 \\
\hline 17 & State Street & 1.27 & Travelers & 1.63 \\
\hline 18 & CME Group & 1.18 & Washington Mutual & 1.61 \\
\hline 19 & ACE Ltd. & 1.15 & Lehman Brothers & 1.59 \\
\hline 20 & Capital One Financial & 1.06 & Allstate & 1.56 \\
\hline 21 & $\mathrm{BB} \& \mathrm{~T}$ & 1.00 & CME Group & 1.46 \\
\hline 22 & Chubb & 0.99 & Capital One Financial & 1.41 \\
\hline 23 & Allstate & 0.93 & Hartford Financial & 1.40 \\
\hline 24 & Charles Schwab & 0.93 & Suntrust Banks & 1.35 \\
\hline 25 & T. Rowe Price & 0.89 & State Street & 1.28 \\
\hline 26 & Franklin Resources & 0.87 & AFLAC & 1.23 \\
\hline 27 & $\mathrm{AON}$ & 0.82 & $\mathrm{PNC}$ & 1.11 \\
\hline 28 & Equity Residential & 0.81 & Regions Financial & 1.02 \\
\hline 29 & Marsh \& McLennan & 0.81 & Loews & 1.02 \\
\hline 30 & SunTrust Banks & 0.80 & Franklin Resources & 1.01 \\
\hline 31 & Ameriprise Financial & 0.78 & Charles Schwab & 0.98 \\
\hline 32 & Public Storage & 0.77 & $\mathrm{BB} \& \mathrm{~T}$ & 0.98 \\
\hline 33 & Vornado Realty Trust & 0.74 & Fifth Third Bancorp & 0.98 \\
\hline 34 & Northern Trust & 0.73 & Chubb & 0.97 \\
\hline 35 & $\mathrm{HCP}$ & 0.73 & SLM & 0.97 \\
\hline 36 & Progressive & 0.71 & Simon Property & 0.93 \\
\hline 37 & Loews & 0.67 & ACE Ltd. & 0.91 \\
\hline 38 & Boston Properties & 0.66 & National City & 0.82 \\
\hline 39 & Host Hotels \& Resorts & 0.64 & Countrywide Financial & 0.81 \\
\hline 40 & Fifth Third Bancorp & 0.64 & Lincoln National & 0.79 \\
\hline
\end{tabular}

This table reports the XLF weights on $12 / 30 / 2010$ and $07 / 30 / 2007$. On $12 / 30 / 2010$, there were 81 companies in XLF; on $07 / 30 / 2007$, there were 96 companies. This table reports the relative market capitalizations of the top 40 holdings of the index. 
Table B: $\Delta$-Matched Basket-Index Spreads on Out-of-the-Money Options

\begin{tabular}{|c|c|c|c|c|c|c|c|}
\hline & & \multicolumn{2}{|c|}{ Financials } & \multicolumn{2}{|c|}{ Non-financials } & \multicolumn{2}{|c|}{ F Minus NF } \\
\hline & & Puts & Calls & Puts & Calls & Puts & Calls \\
\hline & & \multicolumn{6}{|c|}{ Panel I: $T T M=365$} \\
\hline \multirow{3}{*}{ Full Sample } & mean & 1.69 & 0.24 & 1.11 & 0.21 & 0.59 & 0.03 \\
\hline & std & 1.89 & 0.16 & 0.69 & 0.09 & 1.44 & 0.10 \\
\hline & $\max$ & 12.46 & 0.49 & 4.13 & 0.36 & 9.07 & 0.44 \\
\hline \multirow[t]{3}{*}{ Pre-Crisis } & mean & 0.81 & 0.32 & 0.91 & 0.25 & -0.10 & 0.07 \\
\hline & std & 0.20 & 0.06 & 0.44 & 0.05 & 0.34 & 0.05 \\
\hline & $\max$ & 2.27 & 0.49 & 3.09 & 0.36 & 0.95 & 0.20 \\
\hline \multirow[t]{4}{*}{ Crisis } & mean & 3.79 & 0.06 & 1.57 & 0.11 & 2.22 & -0.06 \\
\hline & std & 2.39 & 0.17 & 0.90 & 0.10 & 1.71 & 0.13 \\
\hline & $\max$ & 12.46 & 0.37 & 4.13 & 0.29 & 9.07 & 0.44 \\
\hline & & \multicolumn{6}{|c|}{ Panel II: $T T M=30$} \\
\hline \multirow[t]{3}{*}{ Full Sample } & mean & 0.30 & 0.14 & 0.16 & 0.12 & 0.15 & 0.02 \\
\hline & std & 0.33 & 0.06 & 0.14 & 0.05 & 0.27 & 0.09 \\
\hline & $\max$ & 2.46 & 0.27 & 0.65 & 0.24 & 1.86 & 0.32 \\
\hline \multirow[t]{3}{*}{ Pre-Crisis } & mean & 0.17 & 0.16 & 0.13 & 0.11 & 0.04 & 0.05 \\
\hline & std & 0.06 & 0.05 & 0.11 & 0.05 & 0.12 & 0.07 \\
\hline & $\max$ & 0.38 & 0.27 & 0.51 & 0.24 & 1.00 & 0.32 \\
\hline \multirow[t]{3}{*}{ Crisis Sample } & mean & 0.62 & 0.10 & 0.23 & 0.14 & 0.39 & -0.04 \\
\hline & std & 0.48 & 0.07 & 0.16 & 0.05 & 0.37 & 0.08 \\
\hline & $\max$ & 2.46 & 0.27 & 0.65 & 0.24 & 1.87 & 0.25 \\
\hline
\end{tabular}

This table reports summary statistics for the basket-index spread in the cost of insurance per dollar insured. Numbers reported are in cents per dollar of strike price. The full sample covers $1 / 2003-6 / 2009$. The pre-crisis sample covers $1 / 2003-7 / 2007$. The crisis sample covers $8 / 2007-6 / 2009 . \Delta$ is 20 . In the top half of the table, time-to-maturity is 365 days, in the bottom half it is 30 days. 